\title{
SCALE STRUCTURE, DEGREE MODIFICATION, AND THE SEMANTICS OF GRADABLE PREDICATES
}

\section{CHRISTOPHER KENNEDY}

Northwestern University

\author{
Louise MCNALLY
}

Universitat Pompeu Fabra

In this article we develop a semantic typology of gradable predicates, with special emphasis on deverbal adjectives. We argue for the linguistic relevance of this typology by demonstrating that the distribution and interpretation of degree modifiers is sensitive to its two major classificatory parameters: (1) whether a gradable predicate is associated with what we call an open or closed scale, and (2) whether the standard of comparison for the applicability of the predicate is absolute or relative to a context. We further show that the classification of an important subclass of adjectives within the typology is largely predictable. Specifically, the scale structure of a deverbal gradable adjective correlates either with the algebraic part structure of the event denoted by its source verb or with the part structure of the entities to which the adjective applies. These correlations underscore the fact that gradability is characteristic not only of adjectives but also of verbs and nouns, and that scalar properties are shared by categorially distinct but derivationally related expressions.*

1. Degree modification in deverbal gradable adjectives. Among the many observations made in Bolinger's (1972) classic study of degree expressions in English, two stand out. First, degree modifiers in English have distributions that cannot be given a purely syntactic explanation. Consider, for example, the behavior of well, much, and very. At a superficial level, these three modifiers appear to have very similar syntactic and semantic properties: they all apply to deverbal gradable adjectives, and they all raise the degree to which the deverbal adjective holds of its subject. In 1, for example, the addition of the degree modifiers increases the degree to which the properties are claimed to hold of their respective subjects in roughly the same way.

(1) a. Martin Beck was (well) acquainted with the facts of the case.

b. Their vacation was (much) needed.

c. Al was (very) surprised by the results of the election.

Despite these similarities, however, according to our intuitions and those of other speakers we have consulted, these modifiers differ in terms of their acceptability with different adjectival participles. In fact, as shown by the following examples, their distributions are largely complementary (see Knowles 1974 for discussion of the complementarity of very and much). ${ }^{1}$

(2) a. Beck is well/??very/??much acquainted with the facts of the case.

b. We'll be surrounded by dozens of people-you'll be well/??very/??much protected.

\footnotetext{
*We are grateful to Violeta Demonte, Delia Graff, Irene Heim, Beth Levin, Mark Richard, and Roser Saurí; to audiences at the University of California, Santa Cruz, the University of Southern California, Northwestern University, Universitat Pompeu Fabra, Universität Tübingen, the Zentrum für Allgemeine Sprachwissenshaft in Berlin, the Instituto Universitario Ortega y Gasset in Madrid, and Université Paris 7; and to two referees and the editors of Language for very helpful comments on the material discussed in this article. Portions of this material were presented at the 1999 Colloquium on Generative Grammar, TALN 1999, and the First International Workshop on Generative Approaches to the Lexicon, and we also thank the audiences there. This article is based on work supported by the National Science Foundation under Grant No. 0094263 and by the Generalitat de Catalunya.

${ }^{1}$ Throughout this article, '??' is used to mark examples that, according to our intuitions, are not felicitous. The source of this infelicity in examples like 2-4 on our analysis, as we show below, is a violation of the selectional restrictions imposed by the degree modifier on the adjectives it modifies. We use '\#' to indicate that an example is contradictory, while ungrammaticality is marked, as usual, by '*'.
} 
c. By the time it reached the Manchester Palace, it had become a well/ ??very/??much documented tour.

d. But that was no longer true at election time: as the election approached, the highly educated became less interested, and those who were not well/ ??very/??much educated became more interested.

(3) a. But the heavy rain has been welcomed by the British Waterways, as a much/??well/??very needed boost for its canals and reservoirs which have been kept low during this year's long, hot summer.

b. When the results for beech trees were disclosed, they were nearly identical to the much/??well/??very criticised FoE survey of 1985 .

c. Even at the then much/??well/??very praised Alfort school, their fouryear course was considered to be too long.

d. Fortunately, with much/??well/??very appreciated financial help ... the workshop was organised and held successfully.

(4) a. A very/??well/??much surprised face peered out of the window.

b. Kim was very/??well/??much worried by the diagnosis.

c. Ron Weasley is very/??well/??much frightened of spiders.

d. 'We have people very/??well/??much interested in the site,' he told the committee.

These judgments are mirrored by distributional asymmetries in corpus data, as illustrated by the numbers in Table 1 . These counts are from the first edition of the British National Corpus (BNC; http://info.ox.ac.uk/bnc) and reflect the number of hits in a search of approximately 100 million words. While the distributions are not absolutely complementary (a fact about which we have more to say in §6), the contrasts are striking.

$\begin{array}{lrrr} & \text { WELL } & \text { VERY } & \text { MUCH } \\ \text { acquainted } & 56 & 0 & 0 \\ \text { protected } & 58 & 2 & 0 \\ \text { documented } & 213 & 0 & 1 \\ \text { educated } & 78 & 3 & 0 \\ \text { needed } & 2 & 0 & 211 \\ \text { criticised } & 0 & 0 & 19 \\ \text { praised } & 1 & 0 & 17 \\ \text { appreciated } & 12 & 0 & 124 \\ \text { surprised } & 0 & 151 & 1 \\ \text { worried } & 0 & 192 & 0 \\ \text { frightened } & 0 & 92 & 0 \\ \text { interested } & 0 & 335 & 10\end{array}$

TABLE 1. Distribution of degree modifiers in the first edition of the British National Corpus.

A first hypothesis to explain these facts, or at least the unacceptability of very in 2 and 3, would be that these participles either are not adjectives or are not gradable. As shown by the examples in 5 and 6 , very is restricted to modifying expressions that are both adjectives and gradable. The modifier much also requires its argument to be gradable (Doetjes 1997), though it does not show the same sorts of category restrictions.

(5) a. *He is very a boy/a very boy. (cp. He is very much of a boy.)

b. *That candidate is very to the left of the center. (cp. That candidate is very far/well to the left of the center.) 
(6) a. ??That bomb is very atomic.

b. ??Richard Nixon, a very former president, resigned before he was impeached.

This hypothesis cannot be correct, however. First, the facts in 7 show that many participles that do not cooccur with very allow negative un-prefixation, a property of adjectives but not of verbs.

(7) a. unacquainted, unprotected, undocumented, uneducated

b. unneeded, uncriticized, unpraised, unappreciated

Second, they can appear as complements to copular verbs such as seem,feel, or become, yet another property of adjectives but not of verbs (data from the BNC).

(8) a. I became acquainted with her brother Pavel Sergeevich Popov, a university professor.

b. And in the delirium of recognising her power she felt protected, safe in his arms.

c. Second, this cladogram is an exercise in inference because many of the extinct groups remain poorly documented ...

d. An alternative to the traditional means of funding social services seems needed.

e. But Louisa ... grew up with a very unreal need to feel praised ...

f. However, as the role of radioactive decay in generating heat in the Earth's interior became appreciated, the notion of a contracting Earth was rejected.

Finally, the fact that these participles are gradable is shown by their appearance in comparative constructions, a property that holds only of gradable predicates. This is illustrated by the BNC data in 9 .

(9) a. But as I became more acquainted with this set and stopped rushing from impossible passage to impossible passage, hoping against hope that at some point he would lose his balance and tumble like a second-rate trapeze artist off his swing, I was unwittingly dragged in to a more sinister, melancholic side to his playing.

b. The darker your skin, the more protected it is ...

c. Except for the Baptists, the influx did not lower the trend towards a more educated ministry: the total of all Baptist ministers without any formal higher education was only eighteen percent by 1901 .

d. Not surprisingly one finds a greater number of narratives of the miracles of dead saints in France than in Germany, because they were more needed there.

e. I think there is still unfortunately a need for women to do that; I think they're often more criticised, especially in environments where there are fewer of them and where historically there have been fewer.

f. It seems that staff often feel less appreciated than in fact they are by parents, and probably vice versa.

We therefore conclude that the facts in 2-4 can be explained neither in terms of a category mismatch nor in terms of the nongradability of the predicate: these deverbal expressions are gradable adjectives (see also Borer 1998:92-93).

Bolinger's second important observation, which echoes an earlier point made by Sapir (1944), is the obvious but mostly neglected fact that gradability is a property not just of adjectives, but of nouns, verbs, adverbs, and prepositions as well (though see 
Doetjes 1997, Kennedy \& McNally 1999, Hay et al. 1999, Tsujimura 2001, Vanden Wyngaerd 2001, Paradis 2001, and Wechsler 2005 for examples of recent work exploring these connections). Given the fact that the adjectival expressions we are interested in here are derived from (or related to) verbs, we should ask whether there is some regular correspondence between aspects of verb meaning and aspects of adjective meaning. In particular: are there underlying similarities in the kind of gradability they manifest? Put another way, is it accidental that the various participles in $2-4$ show the behavior that they do, or does some property of the source verb determine the behavior of the adjectival form with respect to degree modification?

The purpose of this article is twofold. First, we use the distribution of degree modifiers as a departure point for developing a semantic analysis of gradable predicates that supports a typology parameterized along two core features. The first is the structure of the scale that a gradable property uses as a basis for ordering the objects in its domain (cf. Rotstein \& Winter 2004), in particular, whether the scale is fully closed (has a minimum and maximum value), partly closed (has only a minimum or maximum value, but not both), or fully open (has no minimum or maximum value). The second feature is the nature of the standard of comparison with respect to which a particular use of a gradable property is evaluated: put roughly, whether it is fixed contextually (as with an adjective like tall, which may be true of an object in one context and false in another), or whether it is determined without reference to context (as in the case of empty, which simply requires its argument to be devoid of contents). The fact that degree modifiers are sensitive to these features is evidence that they are significant components of the lexical semantic representations of gradable expressions. ${ }^{2}$

Our second goal in this article is to demonstrate that the scalar properties of gradable expressions are largely predictable from properties of the events to which they are related or of the individuals to which they apply. This result reinforces the larger claim advanced by Bolinger and Sapir: gradability is a fundamentally important semantic property, whose influence extends beyond adjectives to other lexical categories. Although our discussion is limited to English, we consider the elements of the proposed typology fundamental enough that we would expect to find them relevant for the analyses of other languages as well, and studies such as Tsujimura 2001 for Japanese and Demonte 2004 for Spanish indicate that this is in fact the case. In short, the generality of scale structure, its importance for a wide range of linguistic phenomena, and the relative simplicity of the typology of scales that we develop thus justify a prominent place for scale structure in natural language semantics.

2. The SEMANTIC TYPe OF GRADABLE PREDICATES. We begin by laying out our basic assumptions about the semantic analysis of gradable adjectives. A well-known property of predicative uses of gradable adjectives like tall and expensive is that their interpretations are context-dependent: what counts as tall or expensive may vary from context to context. One way to account for this variation is to characterize the truth conditions of such predicates in terms of a contextually defined STANDARD OF COMPARISON, as in the paraphrases of 10a,b given in 11a,b (see e.g. Sapir 1944, Wheeler 1972, Bartsch \& Vennemann 1973, McConnell-Ginet 1973, Kamp 1975, Lewis 1979, Klein 1980, 1991, Bierwisch 1989, Ludlow 1989, Kennedy 1999b, Graff 2000, Barker 2002).

\footnotetext{
${ }^{2}$ Paradis (2001) also provides a number of empirical arguments that the distribution of degree modifiers correlates with the scalar properties of gradable adjectives, though she does not develop a semantic analysis of modifiers or a formal characterization of adjectival scale structure to account for these facts.
} 
(10) a. Michael Jordan is tall.

b. The Mars Pathfinder mission was expensive.

(11) a. Michael Jordan's height exceeds a standard of tallness.

b. The cost of the Mars Pathfinder mission exceeded a standard of expensiveness.

The standard of comparison is itself determined relative to a COMPARISON CLASS of objects that are similar in some way to whatever is being discussed (Klein 1980); the result is that the truth conditions of sentences like those in 10 may vary. For example, in a conversation about the cost of various missions to outer space, the comparison class for expensive might include many things that are quite a bit more expensive than the Mars Pathfinder mission. (One of the successes of the Pathfinder mission was that its cost was low relative to comparable NASA projects.) If the standard of comparison is set correspondingly high, then $10 \mathrm{~b}$ is false. In contrast, in a discussion about things with the name 'Pathfinder', the comparison class might include compasses, mountain bikes, and sport utility vehicles, as well as missions to Mars. The standard of comparison should therefore be quite a bit lower, and 10b would be true.

There are different ways in which this basic analysis can be implemented. The approach that we assume here is one in which gradable adjectives map their arguments onto abstract representations of measurement, or DEGREES, which are formalized as points or intervals partially ordered along some DIMENSION (e.g. height, cost, weight, and so forth; we provide a more detailed account below). The set of ordered degrees corresponds to a SCALE, and propositions constructed out of gradable adjectives define relations between degrees with truth conditions analogous to the paraphrases in 11 . (See Kennedy 1999a,b for an overview of scalar analyses of gradable adjectives and for arguments that a scalar approach is empirically superior to analyses that do not make use of scales or degrees.)

For the semantic type of gradable adjectives, we follow a well-established tradition and analyze them as relations between individuals and degrees (see Seuren 1973, Cresswell 1977, Hellan 1981, von Stechow 1984a, Heim 1985, Bierwisch 1989, Klein 1991). Specifically, a gradable adjective like expensive has the denotation in 12, where expensive represents a measure function that takes an entity and returns its cost, a degree on the scale associated with the adjective. ${ }^{3}$

(12) $\llbracket$ expensive $=\lambda d \lambda x \cdot \operatorname{expensive}(x)=d$

The adjective expensive thus denotes a relation between degrees of cost $d$ and objects $x$ such that the cost of $x$ equals $d .^{4}$

\footnotetext{
${ }^{3}$ A note on framework and notation: We assume a type-theoretic, compositional, extensional semantics with at least a rule of function application for handling the interpretation of complex constituents (Heim \& Kratzer 1998). All of the expressions we discuss in this paper denote functions of one type or another, so for maximum perspicuity, we use predicate logic and the lambda calculus as the metalanguage for representing their contributions to the truth conditions of a sentence. We assume basic familiarity with this notation, but we define important parts of the representations as appropriate (as with expensive above). We use the variables $d, d^{\prime}$ to represent arguments of type 'degree', the variables $x, x^{\prime}, y$ to denote arguments of type 'entity', and the variable $G$ to denote arguments that have the semantic type of gradable adjectives. Finally, we generally omit reference to contextual parameters in our denotations except where relevant.

Putting all of this together, 12 should be read as follows: the denotation of the adjective expensive is the function $g$ from degrees to functions from individuals to truth values such that for any degree $d, g(d)$ returns the function $f$ from individuals to truth values such that for any individual $x, f(x)=1$ if and only if the degree to which $x$ is expensive equals $d$.

${ }^{4}$ The analysis of gradable adjective meanings in terms of an equality relation in 12 is identical to that of Cresswell 1977, but this is not the only option. Many analyses assume a partial ordering relation instead, in order to capture the entailment from, for example, $x$ is ten $\mathrm{cm}$ long to $x$ is nine $\mathrm{cm}$ long, $x$ is eight $\mathrm{cm}$
} 
In this type of approach, the value of the degree argument is determined by degree morphology - in English, comparatives, degree modifiers, and measure phrases - that saturate and impose restrictions on the degree argument. The comparative morphology more ... than, for example, requires the degree argument of a gradable adjective to exceed some other degree (introduced by the than constituent). We return to a detailed discussion of degree morphology in $\$ 6.1$; here we focus on predicates formed out of unmodified gradable adjectives, such as those in 10 .

To keep things fully explicit and compositional, we follow von Stechow 1984a and assume that unmodified APs actually contain a null degree morpheme pos (for POSITIVE FORM) whose function is to relate the degree argument of the adjective to an appropriate standard of comparison (see also Cresswell 1977, Bierwisch 1989, and Kennedy 1999b). ${ }^{5}$ Specifically, we assume that pos encodes the relation standard, which holds of a degree $d$ just in case it meets a standard of comparison for an adjective $G$ with respect to a comparison class determined by $\mathbf{C}$, a variable over properties of individuals whose value is determined contextually (cf. von Stechow 1984a:60; see Kennedy 1999b for arguments that the comparison class variable corresponds to a property rather than a set).

\section{(13) $\llbracket p o s \rrbracket=\lambda G \lambda x \cdot \exists d[\operatorname{standard}(d)(G)(\mathbf{C}) \wedge G(d)(x)]$}

We do not attempt to provide a full specification here of the requirements imposed by the standard relation, since we argue in $\S 4$ below that it must vary depending on lexical features of the adjective (see also Graff 2000 for relevant discussion). In the case of typical examples such as those in 10, however, we assume that this relation requires a degree $d$ to exceed a norm or average on the scale associated with $G$ that is computed based on the comparison class identified by $\mathbf{C}$. Since $\mathbf{C}$ is a free variable whose value must be fixed contextually (possibly by a specialized assignment function; see Lewis 1979, Stanley 2000, 2002, Barker 2002), whether a particular degree exceeds the norm or not is a function of context. This allows for the sort of truth-conditional variability observed above.

For example, composition of pos with expensive returns 14 as the denotation of the predicate (is) expensive.

(14) $\llbracket p o s \rrbracket(\llbracket$ expensive $\rrbracket)=\lambda x \cdot \exists d[\operatorname{standard}(d)(\llbracket$ expensive $\rrbracket)(\mathbf{C}) \wedge$ 【expensive $\rrbracket(d)(x)]$

\footnotetext{
long, and so forth (Kamp 1975, Heim 1985, Klein 1991). Others treat the adjective as directly denoting a measure function and introduce the degree argument and the relational component in the morphology (Bartsch \& Vennemann 1973, Kennedy 1999a,b). Our decision to adopt the equality analysis in 12 is primarily a matter of convenience, because it allows us to state the meanings of degree modifiers in terms of a single template (see $\$ 6.1$ and $n .15$ ), and because it is possible to achieve equivalent semantic results on all three approaches by positing appropriate meanings for degree morphology. (This may have syntactic consequences, though, so if there is an argument to be made for one analysis over the other, it will most likely be a syntactic one.) What is important for our purposes is the point on which all three analyses agree: the denotation of a gradable adjective crucially includes a measure function that maps entities to scales.

${ }^{5}$ We assume a null degree morpheme primarily for convenience, though it should be noted that in some languages (e.g. Mandarin; see Sybesma 1999:27) the positive form is morphologically marked. An alternative assumption would be to assume a rule of interpretation that introduces a default existential quantifier in an AP headed by a gradable adjective with an unsaturated degree argument, producing an AP denotation that is equivalent to what we derive with pos. Since the choice between these two analyses depends on larger questions about the interpretation of implicit arguments and is independent of the concerns of this article, we do not resolve it here.
} 
If the context determines that $\mathbf{C}$ is the propety of being a mission to outer space, then the cost of the Mars Pathfinder mission is required to be quite high (greater than a norm for missions to outer space), and so $10 \mathrm{~b}$ would be judged false. If instead the context determines that $\mathbf{C}$ is the propety of being a thing named 'Pathfinder', then the cost of the Mars Pathfinder mission is allowed to be quite low (greater than a norm for things named 'Pathfinder'), so 10b would be judged true.

Much of the research cited above has been directed toward demonstrating that the assumptions outlined here provide a framework for handling the vagueness of sentences like those in 10, as well as more complex constructions involving various kinds of degree morphology. Our focus here is on a different set of questions: What exactly are the scales associated with gradable adjectives like? How might they vary? Is the standard of comparison for an adjectival predicate always determined in the same way? Can an adjective be associated with more than one type of scale? What factors determine the sort of scale a given adjective uses? In the following sections, we offer preliminary answers to these questions.

We begin by identifying and providing evidence for one crucial structural property of scales: whether they have minimal and maximal elements. We then show that this property correlates to a large degree with the way in which the standard of comparison is determined, and subsequently consider in further detail some of the factors that determine the type of scale and standard value with respect to which an adjective is interpreted. Finally, we show that both the nature of the scale and that of the standard of comparison play a crucial role in the analysis of the degree modifiers very, mисh, and well.

3. Scale structure. Adjectival scales have three crucial parameters, each of which must be specified in the lexical entry of any particular gradable adjective: a set of degrees, which represent measurement values; a dimension, which indicates the kind of measurement (cost, temperature, speed, volume, height, and so forth); and an ordering relation. This means that scales may in principle be distinguished from each other-with linguistic consequences - in three different ways: in terms of properties of the set of degrees, in terms of the dimensional parameter, or in terms of the ordering relation.

A large body of research has established the linguistic significance of the latter two parameters. The ordering relation is the crucial factor distinguishing between antonym pairs like tall/short, empty/full, expensive/inexpensive, accurate/inaccurate, pure/impure, and so forth, which crucially make use of the same dimension and degrees (e.g. both tall and short map their arguments onto corresponding degrees of height) but express inverse ordering relations. This distinction has a number of well-known empirical reflexes, including markedness, the acceptability of measure phrases, and entailment patterns, and explains why examples like 15 are tautologous (see e.g. Seuren 1978, von Stechow 1984b, Cruse 1986, Bierwisch 1989, Rullmann 1995, Kennedy 2001).

(15) The Sears Tower is taller than the Empire State Building if and only if the Empire State Building is shorter than the Sears Tower.

The dimensional parameter is the primary feature that distinguishes (nonantonymous) gradable adjectives from each other: tall and flexible both express positive orderings, but the first involves one with respect to height (or perhaps something more abstract, like linear extent) and the second one with respect to flexibility. An empirical reflex of this distinction is the phenomenon of incommensurability (see Klein 1991, Kennedy 1999b). As shown by the examples in 16, it is possible to construct potentially quite complex comparisons out of distinct gradable adjectives as long as they map their 
arguments onto scales that share the same dimension. Thus, wide and tall in 16a both involve orderings along a dimension of linear extent, and long and old in 16b both involve orderings with respect to temporal extent. ${ }^{6}$

(16) a. They call him 'The Bus' because he's kind of as wide as he is tall. (National Public Radio broadcast, 1/26/02)

b. [This comparison] is unfair both to him and the quarterbacks like Dan Marino and John Elway who excelled for almost as long as [Peyton] Manning is old. (Chicago Tribune, 11/2/00)

In contrast, comparatives formed out of adjectives that do not use the same dimension are anomalous.

(17) a. ??They call him 'The Bus' because he's kind of as wide as he is punctual.

b. ??These quarterbacks excelled for almost as long as Peyton Manning is talented.

This follows if different dimensions entail different scales, and if comparative morphemes presuppose that the degrees they order come from the same scale (Kennedy 2001).

A central goal of this article is to establish that the structure of the (ordered) set of degrees - the scale itself - is also linguistically significant. In theory, several different structural features could be important, including whether a scale is finite or infinite, whether it is dense or discrete, whether it contains minimal or maximal elements or not, and so forth. Determining the full range of structural variation in scales that natural languages are sensitive to would require an empirical investigation that goes beyond the scope of a single article, however, so our strategy here is to focus on just one of these parameters: whether a scale is OPEN (lacks a minimal element, a maximal element, or both) or CLOSED (has minimal and maximal elements).

This distinction appears to be exactly what we need to characterize the difference between the adjective pairs in 18a and those in 18b: the former describe properties that have maximal and minimal values, while the latter describe properties that do not. ${ }^{7}$

(18) a. full, closed, invisible

b. long, expensive, old

Empirical evidence in favor of this distinction comes from the distribution of PROPORTIONAL MODIFIERS like half and mostly or most of the way, which are acceptable with adjectives like those in 18a and unacceptable with adjectives like those in 18b. This is illustrated by the contrasts in 19 and 20 (see Lehrer 1985, Cruse 1986, Hay 1998, Kennedy \& McNally 1999, Paradis 2001). (Note that the choice of individual to which the adjective is applied is crucial, about which we say more in §5.)

(19) Closed scale adjectives

a. The glass is half/mostly full.

b. Her eyes were half/most of the way closed.

c. These images are half/mostly invisible.

\footnotetext{
${ }^{6}$ The pairs of adjectives still encode different measure functions corresponding to different perspectives on this dimension, though-wide corresponds to a horizontal perspective on linear extent, and tall to a vertical one-and so impose different orderings on the individuals to which they apply.

${ }^{7}$ This claim might seem counterintuitive for the adjectives in $18 \mathrm{~b}$, since it seems natural to assume that old uses a scale with a minimal degree corresponding to an age of 0 , expensive one with a degree that represents a cost of 0 , and so forth. However, the unacceptability of maximizing modifiers with their antonyms, which use the same scale but impose the opposite ordering (so that the maximum of one antonym is the minimum of the other), shows that this claim is correct (Lehrer 1985). We explain this point in detail below.
} 
(20) Open scale adjectives
a. ??The rope is half/mostly long.
b. ??A 15-year-old horse is half/mostly old.
c. ??That car was half/mostly expensive.

The contrasts in 19 and 20 can be accounted for via semantic requirements imposed by the proportional modifiers. Assuming that half and mostly/most of the way have interpretations along the lines of those in 21 , where $S_{G}$ represents the scale associated with a gradable adjective $G$ and diff is a function that returns the difference between two degrees, they are compatible only with adjectives that map their arguments onto scales with maximal and minimal elements. (There are slight differences in the distributions of mostly and most of the way, but for the purpose of making this point about closed scales we can treat them as synonymous.)

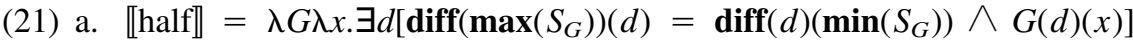
b. $\llbracket$ mostly/most of the way $=\lambda G \lambda x \cdot \exists d\left[\operatorname{diff}\left(\max \left(S_{G}\right)\right)(d)<\operatorname{diff}(d)\right.$ $\left.\left(\min \left(S_{G}\right)\right) \wedge G(d)(x)\right]$

A derivation for halffull, for example, would thus be as shown in 22 (where $S_{f}$ represents the scale associated with full); what we end up with is a property that is true of an object if its degree of fullness corresponds to the midpoint of the scale.

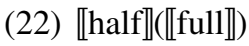

$$
\begin{aligned}
= & \lambda G \lambda x \cdot \exists d\left[\operatorname{diff}\left(\max \left(S_{G}\right)\right)(d)=\operatorname{diff}(d)\left(\min \left(S_{G}\right)\right) \wedge G(d)(x)\right](\llbracket \text { full } \rrbracket) \\
= & \lambda x \cdot \exists d\left[\operatorname{diff}\left(\max \left(S_{f}\right)\right)(d)=\operatorname{diff}(d)\left(\min \left(S_{f}\right) \wedge \llbracket \text { full } \rrbracket(d)(x)\right]\right. \\
= & \lambda x \cdot \exists d\left[\operatorname{diff}\left(\max \left(S_{f}\right)\right)(d)=\operatorname{diff}(d)\left(\min \left(S_{f}\right)\right) \wedge\left[\lambda d^{\prime} \lambda y \cdot \mathbf{f u l l}(y)=\right.\right. \\
& \left.\left.d^{\prime}\right](d)(x)\right] \\
= & \lambda x \cdot \exists d\left[\operatorname{diff}\left(\max \left(S_{f}\right)\right)(d)=\operatorname{diff}(d)\left(\min \left(S_{f}\right)\right) \wedge \operatorname{full}(x)=d\right]
\end{aligned}
$$

The reason why the adjectives in 19 must have closed scales should be obvious: if the scale associated with an adjective accepting, for example, half lacked either a minimal or a maximal element, it would be impossible to calculate differences relative to minimum and maximum values on the scale and thus to identify the midway point required by the degree modifier.

Having shown evidence for the existence of totally closed scales, we now turn to the other logical possibilities. Starting from the assumption that scales may or may not have maximal and minimal elements, there are three additional variations to consider: a scale may have neither a minimal nor a maximal element, it may have a minimal but no maximal element, or it may have a maximal but no minimal element. The first option corresponds to a totally open scale; the second and third options are lower closed and upper closed, respectively.

To make things precise, let us assume that degrees are values that are isomorphic to the real numbers between 0 and 1 . Note that we do not need to assume that scales are actually constructed out of numbers (i.e. that gradable adjectives actually map their arguments onto numerical values), though this is one way of formalizing them (see Klein 1991 for discussion). What is important is that whatever the ontological status of degrees-whether they correspond to numbers, equivalence classes of objects in a model (Cresswell 1977), mental constructs (Bierwisch 1989), or something else-they can vary with respect to (at least) the open/closed distinction.

We represent the four hypothesized scale structures as in 23, where $R$ and $\triangle$ represent the ordering relation and dimension for the scale, respectively. 
(23) A typology of scale structures
a. $\left\langle D_{(0,1)}, R, \triangle\right\rangle$ (TOTALLY) OPEN SCALE
b. $\left\langle D_{[0,1)}, R, \triangle\right\rangle$ LOWER CLOSED SCALE
c. $\left\langle D_{(0,1]}, R, \triangle\right\rangle$ UPPER CLOSED SCALE
d. $\left\langle D_{[0,1]}, R, \triangle\right\rangle$ (TOTALly) Closed SCALE

Scales that are open on the lower end include all of those degrees that approach the limit of 0 but lack a degree whose value is less than that of all the others in the set; scales that are closed on the lower end include such a minimal value, equal to 0 . Analogously, scales that are open on the upper end include all of those degrees that approach the limit of 1 but lack a degree that is greater than all the others in the set; those that are closed on the upper end have a maximal degree whose value is 1 .

Just as we used proportional modifiers to identify adjectives associated with closed scales, we can use the distribution of maximality modifiers such as $100 \%$, completely, and fully to identify those adjectives that manifest the other scale types. In order to get full use out of this diagnostic, however, we need to take adjectival polarity into account. Recall that positive and negative pairs of adjectives make use of the same set of degrees and an ordering along the same dimension, but the orderings are the inverse of each other. ${ }^{8}$ The feature of polarity that we are concerned with here is the following: if the positive member of an antonym pair has a maximal degree, then this corresponds to the minimal degree for the negative adjective, and vice versa. This is most clearly illustrated by a pair like full/empty: if a cup is maximally full, then it is minimally empty (not empty at all); likewise, if it is maximally empty, then it is minimally full (not full at all).

With this in mind, we can now use endpoint-oriented modifiers to determine whether all of the scale types listed in 23 are attested. Given the assumptions about polarity outlined above, we predict that modifiers that pick out maximal degrees should be acceptable with positive adjectives only if they use a scale with a maximal element, and with negative adjectives only if they use a scale with a minimal element. In other words, the four scale types should give rise to the pattern of acceptability in 24 for the indicated degree modifier/polar adjective collocations.

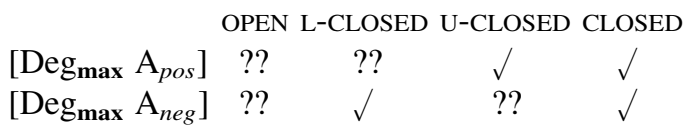

As shown by the following examples, we find pairs of antonyms that share the same scale and that manifest each of the patterns predicted to exist. ${ }^{9}$

\footnotetext{
${ }^{8}$ The antonyms tall and short, on this view, include the measure functions in (ia) and (ib), respectively, where the domain $H \subseteq U$ is that subset of the universe that includes just objects with some height value.

(i) a. tall: $f: H \subseteq U \rightarrow\left\langle D_{(0, \infty)}, \leq\right.$, height $\rangle$

b. short: $g: H \subseteq U \rightarrow\left\langle D_{(0, \infty)}, \geq\right.$, height $\rangle$

${ }^{9}$ Modifiers of maximality like completely and totally have an additional use that is roughly synonymous with very; the true maximality use and this latter use are distinguished by their entailments. A maximality use entails that the end of a scale has been reached, as shown by the fact that (ia) is a contradiction; a nonproportional use carries no such entailment, thus the contingency of (ib).

(i) a. \#The line is totally straight, though you can make it straighter.

b. I'm totally intrigued by bowling, and Kim is even more intrigued by it than I am.

Although we cannot explore here the question of why these modifiers would come to have such a use, our intuition is that it might have originated in a hyperbole or metaphor based on something that was originally literally interpreted along the lines of 'All of me is intrigued by bowling', for example.
} 
(25) Open scale pattern

a. Her brother is completely ??tall/??short.

b. The pond is $100 \%$ ??deep/??shallow.

c. Max is fully ??eager/??uneager to help.

(26) Lower closed scale pattern

a. The pipe is fully ??bent/straight.

b. The room became $100 \%$ ??loud/quiet.

c. That author is completely ??famous/unknown.

(27) Upper closed scale pattern

a. We are fully certain/?? uncertain about the results.

b. This product is $100 \%$ pure/??impure.

c. The treatment is completely safe/??dangerous.

(28) Closed scale pattern

a. The room was $100 \%$ full/empty.

b. The flower was fully open/closed.

c. The figure was completely visible/invisible.

Future research should be directed toward fleshing out these distinctions and their consequences in greater detail. For now, however, these modifier facts serve as initial evidence that scale structure is a linguistically significant parameter of variation in gradable adjective meaning.

\section{Scale STRUCTURE AND STANDARD OF COMPARISON.}

4.1. Relative vs. absolute gRAdable adjectives. The distributions of endpointoriented and proportional modifiers are not the only area in which we see the significance of scale structure. A number of recent works have uncovered other empirical consequences of the open/closed-scale distinction in several different empirical domains. For example, Vanden Wyngaerd 2001 argues that the open/closed scale distinction is relevant to the licensing of resultative predicates in Dutch, and Wechsler 2005 makes similar claims for English. Of particular relevance to us is the work of Rotstein and Winter (2004), who argue that this aspect of scale structure correlates with the 'total' vs. 'partial' predicate distinction identified by Yoon (1996). Roughly speaking, a total predicate is one like (is) clean, which is true of an object if it has a maximal degree of cleanliness, while a partial predicate is one like (is) dirty, which is true of an object just in case it has some degree of dirtiness.

Here we would like to claim that the correlation observed by Rotstein and Winter arises specifically because scale structure influences a crucial feature of the interpretation of gradable adjectives in context: the determination of the standard of comparison. As described in $\$ 2$, scalar analyses of gradable predicates assume that the standard of comparison is determined contextually, as a function of some variable in the semantic representation; under our assumptions, this is the comparison class variable introduced by the pos morpheme. An expectation of this type of analysis is that all predicates headed by (unmodified) gradable adjectives should give rise to the sort of vagueness observed with tall and expensive. This is not the case, however: there are many adjectives that are demonstrably gradable but whose standards of comparison are not contextdependent in the way discussed above.

For example, the adjectives in 29 simply require their arguments to possess some minimal degree of the gradable property they introduce; they do not require that the degree to which the arguments possess this property be greater than some contextually 
determined standard. (These correspond to the Yoon/Rotstein/Winter partial predicates.)

(29) Minimum standards

a. The baby is awake.

b. The spot is visible.

c. The door is open.

d. The rod is bent.

Under normal usage, 29a does not mean that the degree to which the baby is awake surpasses some standard of comparison (for babies), but rather simply means that the baby has a nonzero level of awakeness. Likewise, $29 \mathrm{~b}$ is true as long as even just a small part of the spot can be seen, no matter how faintly, 29c just requires some minimal positive aperture of the door, and $29 \mathrm{~d}$ is true of a rod that is minimally bent.

The adjectives in 30 are similar in not introducing a context-dependent standard, but their arguments are required to possess a maximal degree of the property in question. (These correspond to total predicates.)

(30) Maximum standards

a. The glass is full.

b. The road is flat.

c. The door is closed.

d. The rod is straight.

Example 30a typically means that the glass is completely full, not that its contents fall above some standard context-dependent of fullness, $30 \mathrm{~b}$ is an assertion that the road has no bumps, 30c requires the door to be completely closed, and $30 \mathrm{~d}$ requires a completely straight rod.

Crucially, these facts do not indicate that these adjectives are not gradable. As shown by 31 , they are perfectly felicitous in comparatives, in contrast to what we find with true nongradable adjectives such as those in 32 .

(31) a. The baby is more awake now than it was a few minutes ago.

b. The sign for the Main Street exit is less visible than the one for the Spruce Street exit.

c. The glass isn't as full as I would like it to be.

d. $\operatorname{Rod} A$ is straighter than Rod B.

(32) a. ??The energy we use these days is more nuclear than it was before they built that plant down the road.

b. ??Dinosaurs are more extinct than spotted owls.

We therefore assume that adjectives like those in 29 and 30 have the same semantic type as all gradable adjectives: they are relations between degrees and individuals (type $\langle d,\langle e, t\rangle\rangle)$.

Following Unger 1975, we refer to adjectives like those in 29 and 30 as ABSOLUTE adjectives, and 'ordinary' gradable adjectives with context-dependent standards as RELATIVE adjectives. ${ }^{10}$ There has been little discussion of absolute adjectives in the semantics literature, possibly because there is a strong initial intuition that our characterization of the facts is both too strong and too weak: the adjectives in 29 seem to actually require something significantly more than a minimum standard, and those in 30 seem

\footnotetext{
${ }^{10}$ More precisely, what we are really classifying are adjectives on a given interpretation or interpretations, because it is possible for an adjective to be interpreted with respect to more than one kind of scale and standard. To avoid wordiness, however, we talk simply in terms of 'adjectives'.
} 
to actually allow something less than a maximum standard. These intuitions seem to be supported by examples like those in 33 .

(33) a. I'm not awake yet.

b. The gas tank is full, but you can still top it off. It's not completely full yet.

c. The theater is empty tonight.

Example 33a can be felicitously uttered by someone who is not talking in his sleep. Likewise, most speakers we have consulted feel that full requires its argument only to fall NEAR the maximal value on the scale, pointing to examples like 33b, which does not sound contradictory (but see the examples discussed below in 37). Similarly, 33c can be used to describe a situation in which only a very few people show up to a film in a very large movie theater.

On the whole, it is fairly easy to come up with other 'imprecise' uses of absolute adjectives, calling into question our claim that these adjectives represent a semantic class distinct from relative gradable adjectives. While it is arguably true that in some cases imprecise uses reflect a semantic shift away from a 'default' absolute meaning toward a purely relative one (a point to which we return in $\S 4.3$ ), we nevertheless contend that there are both theoretical and empirical arguments for maintaining the claim that absolute adjectives are semantically distinct from relative adjectives. We address the latter in the next section; here we focus on the former.

From a purely theoretical perspective, it is fairly straightforward to account for imprecise uses of absolute adjectives such as those in 33 while still maintaining the claim that they have maximum or minimum standards. The simplest strategy would be to claim that the propositions conveyed by sentences like these are strictly speaking false, and explain their felicity and informativity in terms of general pragmatic principles governing the interpretation of 'loose talk'. (This is essentially Unger's (1975) position, which he invokes as part of a broader philosophical argument for a skeptical epistemology.)

Formally, we could implement this approach in terms of Lasersohn's (1999) theory of PRAGMATIC HALOS, which provides a framework for determining how much deviation from what is actually true still counts as 'close enough to the truth' in any context to be acceptable and informative. Lasersohn proposes that the context can associate with any expression of the language a set of denotations of the same type as its actual denotation that differ only in some respect that is pragmatically ignorable in the context; this is its pragmatic halo. Any value in the pragmatic halo of an expression $\alpha$ counts as an acceptable and informative approximation of $\alpha$ even if this leads to a proposition that is strictly speaking false. In the case of 33c, for example, we can maintain our claim that the actual denotation of the predicate headed by empty is a property that is true only of objects that are completely empty, but that its pragmatic halo includes properties that are true of objects that are just a little bit less than empty. How much less is determined by context; in this case, by nonlinguistic factors such as the size of the theater, expectations about attendance, and so forth. ${ }^{11}$

\footnotetext{
${ }^{11}$ Alternatively, we could account for imprecise uses in terms of variable 'granularity' of degrees. On this view, the degrees used by a gradable adjective in different contexts would be analogous to different rulers that encode inches, half inches, quarter inches, sixteenth inches, and so forth. Measures will or will not count as maximal depending on how fine-grained these distinctions are: a line that measures $113 / 4$ inches counts as maximal with respect to a ruler that encodes only half-inch increments, but not with respect to one that encodes sixteenth-inch increments.
} 
4.2. Entailments of absolute vs. Relative adjectives. Clear empirical evidence in support of a semantic distinction between relative and absolute adjectives comes from entailment patterns. If the standards associated with absolute adjectives involve maximum and minimum values, then the APs they head should denote properties with the truth conditions shown in 34a,b, where $S_{A}$ stands for the scale associated with the adjectival head, and $\mathbf{m}_{\mathbf{A}}$ is the measure function introduced by the adjective.

(34) a. $\llbracket \mathrm{AP}_{\text {min }} \rrbracket=\lambda x \cdot \exists d\left[d>\min \left(S_{A}\right) \wedge \mathbf{m}_{\mathbf{A}}(x)=d\right]$

b. $\llbracket \mathrm{AP}_{\text {max }} \rrbracket=\lambda x \cdot \exists d\left[d=\max \left(S_{A}\right) \wedge \mathbf{m}_{\mathbf{A}}(x)=d\right]$

Condition $34 \mathrm{a}$ is true of an object as long as it has a nonminimal degree of the gradable property described by the adjectival head, while $34 \mathrm{~b}$ requires its argument to have a maximal degree of the relevant property. These truth conditions are clearly distinct from the ones we discussed for APs headed by relative adjectives in $\$ 2$, which require their arguments to exceed a norm or average of the relevant property for some contextually determined comparison class. We therefore expect that absolute adjectives should give rise to entailments that are distinct both from each other and from relative adjectives.

Before moving to an examination of the entailment patterns of absolute adjectives, however, we need to say a few words about how we derive the truth conditions in $34 \mathrm{a}, \mathrm{b}$ in the first place. Recall that we are assuming that unmodified gradable adjectives must combine with a null degree morpheme pos to derive a property of individuals. Since absolute adjectives have the same semantic type as relative ones (as shown by their acceptability in comparatives; see 31 above), we assume that they must also combine with pos. According to the semantics for pos that we gave in 13, then, what we should derive for minimum and maximum AP denotations are 35a,b, respectively.

(35) a. $\llbracket p o s \rrbracket\left(\llbracket \mathrm{A}_{\min } \rrbracket\right)=\lambda x . \exists d\left[\operatorname{standard}(d)\left(\llbracket \mathrm{A}_{\text {min }} \rrbracket\right)(\mathrm{C})\right.$

$\left.(\mathbf{C}) \wedge \llbracket \mathrm{A}_{\min } \rrbracket(d)(x)\right]$

b. $\llbracket p o s \rrbracket\left(\llbracket \mathrm{A}_{\max } \rrbracket\right)=\lambda x . \exists d\left[\operatorname{standard}(d)\left(\llbracket \mathrm{A}_{\max } \rrbracket\right)(\mathrm{C}\right.$

(C) $\left.\wedge \llbracket \mathrm{A}_{\max } \rrbracket(d)(x)\right]$

In $\S 2$, we left open the question of what it actually means for a degree to satisfy the standard relation. However, if our empirical claims about absolute adjectives are correct, then it must be the case that the nature of this relation is dependent on the adjectival argument of pos. If $G$ is a relative adjective, then the standard relation is as we stated in §2: it requires a degree to exceed a norm or average on the $G$-scale based on the comparison class provided by $\mathbf{C}$. But if $G$ is a minimum-standard absolute adjective, then a degree $d$ satisfies the standard relation just in case it meets the conditions in 34 a (it must be greater than the minimum value of the $G$-scale), and if $G$ is a maximumstandard absolute adjective, $d$ must meet the conditions in $34 \mathrm{~b}$ (it must equal the maximum of the $G$-scale). How to ensure that the standard relation imposes the right conditions for the right adjectives is a project that goes beyond the scope of this article (see Kennedy 2003 for a proposal), so we make the simplifying assumption here that absolute and relative adjectives include lexical information that ensures that their standards are fixed appropriately in the positive form. If this proposal is correct, then the value of the comparison class variable is irrelevant to the calculation of the truth conditions of absolute adjectives. We return to this prediction in $\$ 6.2$, arguing that it is responsible for the distribution of very.

We are now in a position to examine the entailment patterns of absolute adjectives. First, 34a predicts that for a minimum-standard absolute adjective adj, a denial $x$ is not adj should entail that $x$ has a zero degree of $a d j$-ness, that is, that $x$ posesses no amount of $a d j$-ness at all. The contradictory statements in 36 illustrate that this prediction is borne out. 
(36) a. \#My hands are not wet, but there is some water on them.

b. \#The door isn't open, but it is ajar.

c. \#The spot is not visible, but I can see a little bit of it.

Second, 34b predicts that for a maximum-standard absolute adjective adj, an assertion of $x$ is adj should entail that $x$ has a maximal amount of $a d j$-ness, that is, that nothing can be more adj than $x$. This sort of entailment is difficult to test, since maximumstandard adjectives readily allow imprecise uses (see the discussion of 33 above), but the examples in 37 involve cases in which an imprecise interpretation is highly unlikely (and see Unger 1975 for arguments that it is possible to force a precise interpretation by adding focal stress to the adjective). B's response in 37 a is readily understood as a joke, but note that the joke would not be possible if A's assertion did not, strictly speaking, entail that B's glass was $100 \%$ empty. And according to our intuitions, dead and complete, unlike full, for example, are rarely (if ever) used imprecisely, hence the outright oddness of $37 \mathrm{~b}$ and the sense of correction or exception in $37 \mathrm{c} .^{12}$

(37) a. A: Your glass is empty; let me get you another beer.

B: No it's not-there are still a few drops left in it.

b. \#The plant is dead, though one part of it still appears to be alive.

c. \#The paper is complete. I just have to write the conclusion.

In contrast, since the truth conditions for a relative adjective entail only that its argument falls above a contextually determined standard of comparison, neither of these entailments should hold. This is correct.

(38) a. Sam is not tall, but his height is normal for his age.

b. That film is interesting, but it could be more interesting.

A related argument involving entailments is discussed in Cruse 1986 and Rotstein \& Winter 2004. As shown by the examples in 39, there exist pairs of antonyms such that negation of one form entails the assertion of the other.

(39) a. The door is not open (closed). $\models$ The door is closed (open).

b. The table is not wet (dry). $\vDash$ The table is dry (wet).

c. The baby is not awake (asleep). $\models$ The baby is asleep (awake).

The explanation for this is straightforward: both members of the pairs in 39 are absolute adjectives, but the positive adjectives impose minimum standards while the negative adjectives impose maximum standards. Since a minimal positive degree corresponds to a maximal negative degree on the same scale, the entailment relations in 39 follow from the truth conditions in 34 (recall the discussion of polarity in $\$ 3$ ).

Relative antonyms do not give rise to the same entailment patterns, as illustrated by 40 .

(40) a. The door is not large (small). $\not \neq$ The door is small (large).

b. The table is not expensive (inexpensive). $\not \neq$ The table is inexpensive (expensive).

c. The baby is not energetic (lethargic). $\not \neq$ The baby is lethargic (energetic).

Again, this follows from the fact that the standards for both positive and negative relative gradable adjectives are contextually identified and crucially need not be endpoints (in fact, cannot be endpoints if the scales are open). Since a context-dependent standard

\footnotetext{
${ }^{12}$ Although dead is sometimes taken as a paradigmatic case of an ungradable adjective, the felicity of expressions such as half dead or almost dead indicate that it is, in fact, gradable, associated with a closed scale and an upper endpoint standard (see below; see also Rotstein \& Winter 2004).
} 
is determined for particular uses of particular adjectives, it need not be the case that the standard for large, for example, be the same as that of its antonym small, and we allow for the possibility of a 'grey area' between the standards onto which fall objects that are neither large nor small (Sapir's (1944) zONE OF INDIFFERENCE; Klein's (1980) EXTENSION GAP). Indeed, the possibility of such 'borderline cases' is one of the defining properties of vague predicates; see Williamson 1994 for further discussion.

A version of the same entailment test can be used to determine whether the standard corresponds to the upper or lower end of a scale, though this test presupposes that the adjectives being tested have absolute standards, however (cf. Knowles 1974:23-24). If the standard is a maximal degree, then an affirmation such as $x$ is half/partially adj entails that $x$ is not adj, as shown by 41a,b.

(41) a. The plant is half dead. $=$ The plant is not dead.

b. The glass is partially full. $\models$ The glass is not full.

If the standard corresponds to the lower endpoint, however, then such an affirmation entails that $x$ is adj. This is illustrated by the examples in 42 .

(42) a. The door is half open. $\models$ The door is open.

b. The table is partially wet. $\models$ The table is wet.

Finally, relative and absolute adjectives trigger different kinds of entailments in comparative constructions. If the truth conditions associated with minimum- and maximum-standard absolute adjectives are as in 34 , we expect them to generate positive and negative entailments to the unmarked form, respectively (depending on which argument of the comparative we use). This prediction is borne out, as shown by the examples in 43.

(43) a. The floor is wetter than the countertop. $\vDash$ The floor is wet.

b. The floor is drier than the countertop. $\models$ The countertop is not dry.

Assuming that the comparative imposes an asymmetric ordering on its arguments (see the truth conditions for the comparative in §6.1), the comparative in 43a requires the floor to have at least a nonminimal degree of wetness, since otherwise it could not possibly have a greater wetness than the countertop. The truth of the positive then follows directly from the minimum-standard truth conditions in 34a. Similarly, in order for the comparative in $43 \mathrm{~b}$ to be true, it must be the case that the countertop is not maximally dry, since otherwise the floor could not be drier than it. If the standard for dryness is the maximum value on the scale, as stated in $34 \mathrm{~b}$, then it follows that the countertop is not dry.

In comparison, a canonical property of comparatives with relative adjectives is that they do not give rise to positive or negative entailments in the comparative form, as illustrated by $44 a, b$.

(44) a. Rod A is longer than $\operatorname{rod} \mathrm{B} . \not \neq \operatorname{Rod} \mathrm{A} / \mathrm{B}$ is (not) long.

b. Rod A is shorter than $\operatorname{rod} \mathrm{B} . \not \neq \operatorname{Rod} \mathrm{A} / \mathrm{B}$ is (not) short.

This also follows, since the mere fact that one object exceeds another with respect to some relative property tells us nothing about how the objects stand in relation to a contextually determined standard of comparison.

4.3. Relating SCALES AND STANDARDS. The conclusion to be drawn from these facts is that there is a semantic distinction between gradable adjectives with absolute and relative standards. Even though the former have imprecise uses that sometimes make them appear superficially similar to relative adjectives, the data discussed above show that the absolute/relative distinction — whether a gradable adjective has a context-sensi- 
tive or context-insensitive standard-affects entailment patterns, and so is linguistically significant.

This conclusion raises the following question: is there a principled relationship between an adjective's scale structure and its standard value? The data discussed so far suggest the following generalization: gradable adjectives associated with totally open scales have relative standards; gradable adjectives that use totally or partially closed scales have absolute standards. The first of these two generalizations is exceptionless: since open scales lack endpoints, it is impossible for open-scale adjectives to have endpoint standards. While we observe below that the second of these two generalizations is not exceptionless, it does appear that the standards for close-scale adjectives default to an endpoint of the scale: the minimum in some cases (e.g. awake and open), the maximum in others (e.g. asleep and straight).

There are at least two, mutually compatible, explanations for such a default. The first is primarily functional. The endpoints of a totally or partially closed scale provide a fixed value as a potential standard, which in turn makes it possible to assign contextindependent truth conditions to the predicate (greater than a minimum, equal to a maximum). The alternative-and the only option available for adjectives with open scales - is to compute the standard based on some context-dependent property of degrees, as discussed in $\$ 2$. If we assume that interpretations that minimize contextdependence are in general preferred, then closed-scale adjectives should favor an absolute interpretation.

The second explanation has to do with the way in which adjectival properties come to hold of entities. In many cases, an adjectival property comes to be true of an entity by virtue of that entity's having participated in some kind of event or state. As we explain in further detail in the next section, there is a strong correlation between the structure of such an event, the role played by the relevant entity in it, and the satisfaction conditions (including the nature of the scale structure) for the adjectival predication whose truth is supported as a result of the event or state's transpiring. The result, as we see below, is a maximal or minimal absolute standard, depending on the relation of the argument to the event.

5. FACTORS DETERMining SCALES AND STANDARDS. We now turn to the issue of whether an adjective can be associated with more than one kind of scale, and, more generally, to the issue of whether we can predict for an arbitrary adjective what kind of scale structure and standard value it will use. We argue that the scale structure of deverbal adjectives can be predicted based on the event structure associated with the source verb, and that in the case of all adjectives a crucial factor is the boundedness of the adjective's argument (cf. Paradis 2001). We further show that the orientation of an absolute standard - whether it is maximum or minimum - also depends on properties of the aspectual and argument structure of the source verb. Our focus here is on derived adjectives because we believe that these are the best candidates for observing the way that scale structure is determined 'on the fly'. Whether our observations can be extended to an explanation of why different lexical adjectives have the scales they do is an issue we must leave for future work; for now, we assume that the scalar properties of lexical adjectives are encoded in their lexical entries.

5.1. Event Structure And SCAle Structure. Taking as a starting point the class of deverbal gradable adjectives with totally closed scales (those that are acceptable with proportional and endpoint-oriented modifiers), the data that we have observed 
indicate that this class corresponds very closely to the class of verbs that introduce incremental arguments. As pointed out by Krifka (1989, 1992; see also Dowty 1991, Tenny 1995, Jackendoff 1996, Ramchand 1997), what is unique about this class of verbs is that it is possible to establish a homomorphic relationship between the events they denote and their incremental arguments. This homomorphism is captured formally by Krifka in terms of his notion of MAPPING TO OBJECTS, defined as a characteristic of thematic roles $R$ as follows (Krifka 1989:92).

(45) $\forall R\left[\operatorname{MAP}-O(R) \leftrightarrow \forall e \forall e^{\prime} \forall x\left[R(e, x) \wedge e^{\prime} \subseteq_{E} e \rightarrow \exists x^{\prime}\left[x^{\prime} \subseteq_{O} x \wedge R\left(e^{\prime}, x^{\prime}\right)\right]\right]\right]$ In prose, MAP-O guarantees that all subevents $e^{\prime}$ of a given event $e$ with participant $x$ in role $R$ (what Dowty 1991 refers to as the 'incremental theme') involve a part $x^{\prime}$ of $x$. A typical incremental theme is the object of the verb eat: for all subevents of a given event of eating an orange, for example, we can identify unique parts of that orange that were eaten during each of those subevents. Conversely, we know how much of the eating-an-orange event has been completed by examining how much of the orange has disappeared; the homomorphism in this direction is captured by Krifka's analogous notion of MAPPING TO EVENTS (see Krifka 1989:92).

As pointed out by Ramchand (1997), however, there are at least two additional types of incremental arguments: what she calls Pat(ient) $+/-$ and Pat LOC $_{\text {(see also Jackendoff }}$ 1996, Krifka 1998, and Hay et al. 1999). Pat ${ }_{+/-}$arguments are those that undergo an incremental change of state, such as the subject of the verb cool in a sentence like The soup cooled. Those verbs for which a homomorphism can be established between the progress of the event and the location of one of its participants have Pat LOC $_{\text {arguments. }}$ For example, the verb descend in Max descended the staircase entails incremental movement of the subject along a path defined by the direct object. ${ }^{13}$

We claim that it is precisely the homomorphic relation between the incremental theme argument and the corresponding event that is responsible for the scalar properties of adjectives derived from this class of verbs. Specifically, since such adjectival participles measure the degree to which their arguments have participated in the event described by the source verb, their scales should have minimal and maximal values defined as follows: the minimal degree on the scale represents participation in a minimal (sub)event of the appropriate sort by (a minimal part of) the incremental theme (or a minimal degree of the relevant measurable property for Pat $+/$ - arguments, or a minimal movement along the relevant path for $\mathrm{Pat}_{\mathrm{LOC}}$ arguments); the maximal degree on the scale represents participation in the maximal event involving (all of) the incremental theme/ property/path.

As an example, consider loaded, as in 46.

(46) The truck is loaded with hay.

Let us assume, generalizing Dowty's (1991) analysis of spray/load verbs, that the truck is the incremental theme in the loading event described in 46 . We can define a mapping between the progress of the event of loading and a property of the truck, namely, the volume of the material that it holds; the degree to which the truck can be said to be

\footnotetext{
${ }^{13}$ Whether the three types of incremental roles posited by Ramchand are theoretically justified, or whether these different classes of incremental verbs can be subsumed under a single, general semantic analysis, as suggested in Hay et al. 1999, is not a question that we are able to address here. What is important for us is that all of these verbs are similar in the incremental relation between (different aspects of) their arguments and the described events, and that this relation forms the basis for building a closed scale for the adjectival form, as explained below.
} 
loaded corresponds to the degree to which it has progressed through a loading event. Since we can define a beginning point and endpoint for this event (corresponding to when the truck is unloaded and loaded, respectively), we can identify minimal and maximal values for the scale of 'loadedness' of the truck.

The following examples support the generality of the claim that if an adjective is derived from a verb with an incremental argument, that adjective will have a closed scale: these adjectives are compatible with proportional and endpoint-oriented degree modifiers. ${ }^{14}$

(47) 'Classic' incremental theme arguments
a. half eaten cookies
b. a partially written novel
c. a fully paid bill
d. a half prepared talk
e. a completely severed connection

(48) Pat $_{+/}$- arguments
a. partially documented allegations
b. an individual fully acquainted with the facts
c. fully straightened teeth
d. partially frozen liquid
e. a completely covered terrace

(49) Pat $_{\text {LOC }}$ arguments
a. a partially crossed desert
b. a half descended staircase
c. fully raised blinds
d. a completely traversed distance

Now let us consider the implication that, if a participial adjective has a totally closed scale, it is derived from a verb with an incremental argument. If this implication is correct, then those adjectives derived from verbs lacking such arguments should not have closed scales, and it should be impossible to combine them with proportional/ endpoint-oriented modifiers. And indeed, the examples we have found, such as those illustrated in 50, systematically bear out this prediction. Note that these participles are derived from atelic verbs (whether stative or nonstative, as in 50a-d) or from verbs that are telic but in which the theme or experiencer argument is affected holistically (as in 50f) or experiences a change in property that is necessarily mapped onto an open scale (as in 50g).

(50) Adjectives derived from nonincremental theme verbs
a. ??a completely hated/loved/envied/admired neighbor
b. ??fully needed/wanted rest
c. ??a partially regretted action
d. ??a completely looked for reaction
e. ??a completely watched suspect
f. ??a partially kissed/met/punched young man
g. ??a fully worried mother

\footnotetext{
${ }^{14}$ Space precludes explicitly demonstrating that these and the remaining participles discussed in this article are adjectives. However, the reader can confirm for him/herself that the majority of them accept un-prefixation, and those that do not (like hated) occur readily as the complement to predicates like seem. See Levin \& Rappaport 1986 on the question of which participles in English can be adjectival.
} 
If telic verbs with incremental arguments map onto totally closed scales, what should we expect from adjectives derived from atelic verbs such as needed or looked for? If the same sort of homomorphic relation exists between the event structures of atelic verbs and the scale structures of the corresponding adjectives, then such adjectives should have partially closed scales. The minimal (sub)event or state that supports the truthful application of the adjectival property to its argument will map onto the lower endpoint of the scale. Progressively larger subevents will map onto progressively higher points on the scale. However, since atelic verbs describe situations with no natural endpoint, there is no obvious maximal event or state that could correspond to an upper endpoint of the corresponding adjectival scale. The scale should thus be open on the upper end.

Consider for example needed. If the Mediterranean coast needs even just a tiny bit of rain (for example, because it has rained just slightly less than normal for the season), it is entailed that rain is needed. If the drought continues, the degree to which the rain is needed will increase. But just as it makes no sense to talk about the culmination of this need relation (as opposed to its end), it makes no sense to talk about the rain being 'completely needed'.

Observe that the ordering of entities (or events, since they can be needed too) on the need scale in this example is determined by the temporal duration of the need relation that supports the truthful ascription of the adjective. Similarly, most of the modified APs in 51 can be paraphrased as APed for a long time.

(51) a. a much admired statesman

b. much needed rain

c. a much regretted action

d. a much praised piece of work

e. a much looked for treasure

f. a much talked about program

These examples anticipate the analysis of much to be presented in $\S 6.3$, which requires the adjective to have a lower closed scale. Our interest here is that they also show that temporal duration is not the only way to measure need, admiration, and so forth; in fact, the mapping from (verbal) events to (adjectival) scales can be influenced by other aspects of the source verb's meaning.

For example, arguably the most natural reading of much admired is paraphrasable as admired by many people, without necessarily entailing that the admiration has been long lasting; at the same time, a much talked about program might well be one that has been talked about many times, though not necessarily by many different people or for a particularly long time on any given occasion. Adjectives denoting the property of being the object of an emotion, such as admired, loved, or hated, or the experiencer of an emotion, such as worried, also permit readings on which the scalar dimension along which they are measured is one of intensity. For example, a much despised neighbor might be despised by only one individual, but with a passion.

What these facts indicate is that the dimensional parameter of the derived scale, like the structure of the scale, is also a function of the meaning of the source verb. Specifically, any of the various aspects of verb meaning that support measurement (temporal extent, number of occurrences, number of participants, intensity, etc.) can be used to fix the dimensional parameter of the derived adjective's scale. We may assume that any particular adjectival form (needed, admired, etc.) is compatible with several dimensions, one of which must be settled upon in a context of utterance. In the domain of 
lexical adjectives, this phenomenon is known as INDETERMINACY and is illustrated by the dual uses of, for example, long as a measure of temporal or linear extent (see McConnell-Ginet 1973, Kamp 1975, Kennedy 1999b).

In all of these cases, however, the structure of the scale for the derived adjective is constructed in the same way: by mapping from a set of potentially complex events that can be ordered in an algebraic structure as proposed in, for example, Link 1983, Landman 1989, or Lasersohn 1995. Such algebraic structures are formed by summing together larger events out of smaller ones-for instance, various atomic events in which the same statesman is the object of admiration, possibly by a different person each time, or in which the same program is talked about. These events are ordered by increasing size (and complexity), and this ordering, in turn, can map onto a scale that is bounded on the lower end but not on the upper end, since there is in principle no limit to the number of individuals that can admire someone, nor to the number of times an event such as talking about something can be iterated, and so on.

The hypothesis that event structure correlates with scale structure makes an additional prediction: no deverbal adjective should be associated with a scale that is open on the lower end, whether or not it is bounded on the upper end. The reason is that there should always be a minimal event that supports the truth of the adjectival predication and that is homomorphically related to the lower bound on the scale. Evidence that this prediction is correct comes from the fact that, to the best of our knowledge, all deverbal adjectives prefixed with $u n-$, which reverses the polarity of the adjectival scale, accept modification by endpoint-oriented modifiers such as completely (see $§ 3$ above).

5.2. Bounded ARguments, Bounded sCALEs. Although the generalizations described in the previous section are quite robust, one also finds some prima facie counterexamples. One is known. The verb know is stative, and thus atelic, in English. Given what was said in the previous section, we would predict that known would be associated with a scale that is bounded on the lower end but open on the upper end. Nevertheless, examples such as 52, in which the adjective cooccurs with an upper endpoint-oriented modifier, are felicitous.

(52) The effects of that drug are not fully known.

How does know come to be associated with a closed scale? More specifically, what might provide the basis for a homomorphic mapping to that closed scale?

There are two possible answers to this question in the case of known. One would be that the scale structure of known is based on an implicit event of 'coming to know', which has as its culmination the state described by the verb. However, a more interesting and, we think, much more likely answer is that the extension of the adjective's argument provides the basis for building the closed scale. If, for example, an object $x$ is partially known, then one or more individuals stand in a knowing relation to at least some part of $x$; if $x$ is fully known, then one or more individuals stand in a knowing relation to all parts of $x$; and so on. In general, any adjective that can apply not only to the whole of an entity but also to its parts could also be associated with a scale whose structure is based on the part structure of that entity.

A look at the facts supports the systematic ability of an adjective's argument to determine the scale used for interpreting that adjective, including with adjectives that are not deverbal. Consider the adjective hot, for example. Although it rejects modification by an endpoint-oriented adjective when its argument is not easily considered 
bounded, as in 53a, such modification becomes possible when the adjective is applied to something clearly bounded, as in 53b, which is paraphrasable as 'All of the baby's face is hot'.

(53) a. ??Outside it's completely hot.

b. The baby's face is completely hot.

A second source of evidence comes from the vagueness observable in 54, in which we find the modifier half, which, like completely, requires an adjective with a closed scale.

(54) a. The meat is half cooked.

b. The crops are partially frozen.

Example 54a can be understood as entailing that all of the meat is half cooked, but it also can be true in situations in which half of the meat is entirely cooked. In other words, in addition to the scale made available by the event structure of cook-the scale relevant for the first construal of the sentence-cooked can also be associated with a closed scale made available by the part structure of the meat, which is relevant for the second construal of the sentence.

Though we must leave for future research a full analysis of the effects of event structure and the boundedness of the adjective's argument on the determination of scale type, the above examples are sufficient to demonstrate that the scale type of adjectives is often predictable, and that regularities can be established not only between the algebraic part structure of events and scale structure, but also-in a parallel fashionbetween the algebraic part structure of individuals and scale structure.

5.3. Predicting the orientation of absolute standards. We close this section with one final example of the tight relationship between event structure and scale structure: the role that the former plays in determining whether a derived absolute adjective defaults to a minimum or maximum standard.

The data show that in the case of deverbal adjectives, the orientation of the standard depends on the role of the adjective's argument in the event associated with the corresponding verb. Adjectives whose arguments satisfy mapping to objects (see 45 above), such as cut and written, systematically have upper endpoints as standards, while those whose arguments do not, such as acquainted and documented, have lower endpoints as standards. This correlation is exemplified in 55 and 56. The fact that 55a and 55b are mutually entailing supports the claim that the argument of cut satisfies mapping to objects. The fact that 55a does not entail 55c shows that the standard for $c u t$ is the maximum value on the scale (see the discussion in $\$ 4.2$ ).

(55) a. The grass is half cut.

b. Half of the grass is cut.

c. The grass is cut.

A different pattern appears in 56 . Here we see that $56 \mathrm{a}$ and $56 \mathrm{~b}$ are not mutually entailing; rather, 56a entails 56c. This indicates that the (external) argument of $a c$ quainted does not satisfy mapping to objects. And again in contrast to what happens with $c u t$, 56a entails 56d, as expected if the adjective has a minimum standard.

(56) a. Beck is partially acquainted with the facts.

b. ??Part of Beck is acquainted with the facts.

c. Beck is acquainted with part of the facts.

d. Beck is acquainted with the facts. 
The explanation for these correlations can be traced to the relationship between the truth conditions for the adjective and those for the related verbal predication. Consider first the case of the argument satisfying mapping to objects. Because it cannot be asserted that the eventuality corresponding to the participle is completed until the argument has been totally affected in the relevant way, it follows that an adjectival participle truthfully applies to such an argument only if that argument possesses a maximal amount of the relevant (deverbal) property. The result is a maximum standard.

The situation is different in the case of other types of arguments. Since the completion of the eventuality corresponding to the participle does not depend on affecting all of the relevant argument, or affecting that argument in its entirety, it may be asserted that the eventuality is completed even when that argument has been minimally affected. As a result, the adjectival participle may be truthfully applied to such an argument as long as the argument possesses a minimal degree of the relevant property. This derives a minimum standard.

6. The Distribution OF DEGREE MODIFIERS. The central conclusion of $\S \S 3$ and 4 is that scale structure (open vs. closed) and standard value (relative vs. absolute) are grammatically significant properties of individual gradable adjectives. We now return to the issue we started this article with-the distribution of the modifiers very, mисh, and well in adjectival participles - and show that the facts can be explained in terms of these two semantic features.

6.1. The Semantics of Degree modification. Recall from the discussion in $\S 2$ that we are assuming that gradable adjectives - both the relative and absolute varietiesdenote relations between individuals and degrees with interpretations along the lines of 57, where $\mathbf{m}_{\mathbf{A}}(x)$ represents the projection of $x$ onto the scale associated with the adjective $A$.

(57) $\llbracket \mathrm{A} \rrbracket=\lambda d \lambda x \cdot \mathbf{m}_{\mathbf{A}}(x)=d$

We further assume that degree morphemes denote functions from (gradable) adjective meanings to properties of individuals (they are of type $\langle\langle d,\langle e, t\rangle\rangle,\langle e, t\rangle\rangle$ ) whose role is to saturate the degree argument of the adjective, and we characterize the meanings of degree morphemes in terms of the template in 58 , where $\mathbf{R}$ is some restriction on the degree argument of the adjective. ${ }^{15}$

(58) $\llbracket \operatorname{Deg}(\mathrm{P}) \rrbracket=\lambda G \lambda x . \exists d[\mathbf{R}(d) \wedge G(d)(x)]$

What distinguishes different degree morphemes from each other is the value of $\mathbf{R}$ - the specific restrictions they impose on the adjective's degree argument. We have already seen two distinct illustrations of this in the proportional modifiers and the null pos morpheme; here we examine a few other common degree terms before returning to very, much, and well.

\footnotetext{
${ }^{15}$ We state the truth conditions of degree modifiers in terms of the template in 58, which involves existential quantification over degrees, primarily for convenience and clarity of exposition. In fact, our core proposals allow for the possibility that different degree modifiers introduce different types of quantification, and that some do not have quantificational force at all. The important claim here is that degree modifiers select for gradable predicates and saturate their degree arguments, and so are able to impose restrictions both on the predicate they combine with and on its degree argument.

This choice is not without consequences, however: as pointed out in Kennedy 1999b, an analysis of lesscomparatives in terms of 58 plus a semantic analysis of gradable adjectives in terms of a partial ordering relation leads to tautologous truth conditions. Hence our decision to characterize adjective meanings in terms of an equality relation (see n. 4).
} 
Consider first the case of measure phrases, assuming Klein (1980) is correct in analyzing them as a type of degree term. ${ }^{16}$ A measure phrase like two meters can be assigned a denotation along the lines of 59 , where two meters is a degree on the scale that corresponds to a measure of two meters.

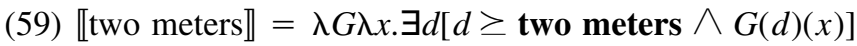

The composition of two meters tall is shown in 60: this phrase denotes a property that is true of an object $x$ if there is a degree that measures at least two meters and $x$ 's height is equal to that. ${ }^{17}$

(60) $\llbracket$ two meters $\rrbracket(\llbracket$ tall $\rrbracket)$

$$
\begin{aligned}
& =\lambda G \lambda x . \exists d[d \geq \text { two meters } \wedge G(d)(x)](\llbracket \operatorname{tall} \rrbracket) \\
& =\lambda x . \exists d[d \geq \text { two meters } \wedge \llbracket \operatorname{tall} \rrbracket(d)(x)] \\
& =\lambda x . \exists d\left[d \geq \text { two meters } \wedge\left[\lambda d^{\prime} \lambda y \cdot \operatorname{tall}(y)=d^{\prime}\right](d)(x)\right] \\
& =\lambda x . \exists d[d \geq \text { two meters } \wedge \operatorname{tall}(x)=d]
\end{aligned}
$$

Comparatives can also be handled in these terms. Assuming for perspicuity that the comparative morpheme and comparative clause (the consituent introduced by than or as) form a constituent at the level of semantic interpretation (Bresnan 1973), the denotations of comparative degree morphology can be stated as in 61 , where $d_{c}$ is the degree introduced by the comparative clause (Heim 1985, Rullmann 1995, Hazout 1995). (We are ignoring here the complicated question of how the interpretation of the comparative clause is compositionally derived; see Gazdar 1980, Hellan 1981, von Stechow 1984a,

\footnotetext{
${ }^{16}$ Treating measure phrases as degree terms correctly predicts their complementary distribution with other degree modifiers.
}

(i) a. *Yao is seven feet very tall.

b. *Yao is very seven feet tall.

Measure phrases do combine with comparative morphology (five feet taller than, seven inches too tall), but here the measure phrase restricts a 'differential' degree introduced by the comparative morpheme that denotes the difference (of height, in this case) between the compared objects rather than the actual degree argument of the adjective. We discuss this issue in more detail in $\$ 6.3$ below.

${ }^{17}$ Two comments are in order. First, this example illustrates the fact that in our analysis, the 'at least' component of the meaning of two meters tall (which is true of a 2.1 meter tall man, etc.) comes from the measure phrase (or the numeral), not from the adjective (see n. 4).

Second, a referee asks how this analysis of measure phrases can account for well-known asymmetries like (ia,b), and for markedness facts in general, given our earlier claim that antonyms like tall and short differ only in the orderings they impose (see $\$ 3$ and n. 8).

(i) a. Yao is seven feet tall.

b. ??Julian is three feet short.

Since our primary theoretical goal in this article has been to establish the linguistic significance of scale structure as a semantic feature of gradable predicates, we have largely ignored the related issues of markedness and antonymy to maintain expository clarity. However, it is easy to show that this contrast can be accounted for within the overall semantic framework we have advocated. Following Seuren 1978, von Stechow 1984b, and Kennedy 2001, assume that degrees are intervals, rather than points, and that polarity is represented as a structural distinction between the sort of degree arguments selected by (positive and negative) gradable predicates, rather than as a difference in underlying ordering relations as stated in $\mathrm{n}$. 8. Roughly, positive adjectives map their arguments onto degrees that range from the lower end of a scale to some point, and negative adjectives onto degrees that range from some point to the upper end of the scale, so that if, for example the value of $\operatorname{tall}(x)$ is the interval $(0, p)$ on the height scale, then $\operatorname{short}(x)$ is the interval $(p, 1)$. Assuming that measure phrases introduce only positive degrees (von Stechow 1984b), the anomaly of (ib) can be explained as a kind of incommensurability (Kennedy 2001).

Whether this analysis of polarity also supports an account of markedness in general is an open question (see Bierwisch 1989). If the basic hypothesis that polarity is based on a structural distinction between degrees is correct, however, it provides yet more evidence of the linguistic significance of scalar representations. 
Heim 1985, 2000, Bierwisch 1989, Hendriks 1995, Rullmann 1995, and Kennedy 1999b, 2002 for various approaches.)

(61) a. 【er/more than $d_{c} \rrbracket=\lambda G \lambda x . \exists d\left[d>d_{c} \wedge G(d)(x)\right]$

b. 【less than $d_{c} \rrbracket=\lambda G \lambda x . \exists d\left[d<d_{c} \wedge G(d)(x)\right]$

c. $\llbracket$ as as $d_{c} \rrbracket=\lambda G \lambda x \cdot \exists d\left[d \geq d_{c} \wedge G(d)(x)\right]$

Composition proceeds exactly as illustrated for measure phases in 60, so that a comparative predicate like more expensive than $d_{c}$ denotes a property that is true of an object $x$ if there is a degree of cost greater than $d_{c}$, and $x$ 's cost equals that.

Because comparatives simply introduce an ordering restriction, they represent the most general sort of degree term, essentially requiring only that their adjectival arguments be gradable in the first place (i.e. of type $\langle d,\langle e, t\rangle\rangle)$. Other degree modifiers, however, have denotations that place more specific restrictions on a gradable predicate's degree argument, and so may have more restricted distributions. In particular, we have already seen that proportional modifiers fix the value of an adjective's degree argument relative to maximum/minimum degrees on an adjective's scale, and so are limited in their distributions to closed-scale adjectives. The modifier completely, for example, has a denotation along the lines of 62 (cf. the analyses of half and mostly in 21 above), which restricts the degree argument of a gradable adjective to being a maximum on the adjective's scale.

\section{(62) $\llbracket$ completely $=\lambda G \lambda x \cdot \exists d\left[d=\max \left(S_{G}\right) \wedge G(d)(x)\right]$}

Assuming that the max function returns a value only for scales with maximal values, this modifier can combine only with gradable adjectives that have scales that are closed on the upper end. Similar remarks hold for modifiers like partially that make reference to minimal values.

The preceding sections have demonstrated that scale structure is not the only significant lexical property of gradable adjectives, however: the nature of an adjective's standard value-whether it is relative or absolute-is also important. We therefore expect to find degree modifiers that are sensitive to standard type as well as scale structure. In the following sections, we argue that the difference in the distributions of very and much is crucially accounted for in these terms. We then turn to the modifier well, which we claim is of a different semantic type from other degree modifiers, but interacts with both the scale structure and standard value of the expression it modifies.

6.2. VERY. Roughly speaking, the difference between, for example, expensive and very expensive is that the latter denotes a property whose meaning is just like the former's, except that the relative standard is raised by some amount. This is illustrated by pairs like the one in 63, which shows that the standard-raising effect of very (in terms of absolute increase of degree) depends on how high the initial standard is determined to be.

(63) a. The international space station is very expensive. (for space projects; large increase from contextual standard of comparison)

b. The coffee at the airport is very expensive. (for coffee; small increase from contextual standard)

Klein (1980) accounts for these intuitions by analyzing a predicate of the form very $A$ in essentially the same way as its simple, unmodified counterpart, with one important difference: whereas the regular contextual standard is a degree that exceeds a norm or average of the relevant property calculated on the basis of an arbitrary, contextually determined comparison class, the very standard is a norm or average calculated in the 
same way but just on the basis of those objects to which the unmodified predicate truthfully applies (see also Wheeler 1972, von Stechow 1984a). For example, in a context in which the standard of comparison for the adjective (phrase) tall is the average degree of height for the comparison class basketball players, the standard of comparison for the AP very tall is an average of height for just the tall basketball players. As a result, some basketball players who count as tall will not count as very tall, and the standard will be effectively raised.

We can implement Klein's analysis directly in our system by analyzing very in essentially the same way that we analyzed the pos morpheme in 13: in terms of the standard relation. In the case of pos, this relation requires the degree argument of an adjective $G$ to exceed a norm for a comparison class determined by the contextual property variable $\mathbf{C}$. In the case of very, however, the comparison class is lexically specified: it is those objects that have the property $G$ in the context of utterance. This is made explicit in 64, which specifies the denotation of very relative to a context $c{ }^{18}$

(64) $\llbracket \operatorname{very} \rrbracket^{c}=\lambda G \lambda x . \exists d\left[\operatorname{standard}(d)(G)\left(\lambda y . \llbracket p o s(G)(y) \rrbracket^{c}\right) \wedge G(d)(x) \rrbracket\right.$

Thus very $A$ is true of an object if the degree to which it is $A$ exceeds a norm or average on the $A$-scale for a comparison class based on those objects that have the property $\operatorname{pos} A$ in the context of utterance. The computation of the very standard is therefore a function of the computation of the pos standard, so the interpretation of very $A$ ultimately relies on the same contextual parameters that are involved in fixing the truth conditions for relative adjectives in general, in particular, the identification of a comparison class.

In fact, the connection between very and relative adjectives is even stronger: in normal usage, absolute adjectives reject modification by very, as illustrated by examples like those in 65 .

(65) a. ??I always leave the door to my office very open. (cp. wide open)

b. ??That drug is currently very available. (cp. widely available)

The adjective dry provides a particularly clear illustration of this restriction, since it has both relative and absolute uses. When dry is used to describe a (more or less) permanent, stable property such as the average degree of moisture in the atmosphere, it has a relative interpretation. Thus the comparative in 66a allows for the possibility that both of the compared objects are dry, and the negation in 66b does not generate a positive entailment to the antonym wet. (See the discussion of these tests in \$4.2.)

(66) a. This region of the country is drier than that one (though both are dry).

b. This region of the country is not dry (but it's not wet either).

If, however, $d r y$ is used to describe a transient property like the amount of moisture on a surface, it has an absolute interpretation, as shown by the fact that the comparative

\footnotetext{
${ }^{18}$ A referee points out that the semantic type of very does not allow for (apparent) recursion in examples like very very surprised, quite quite hungry, really really tall, and so forth. However, there is reason to believe that this is not recursion at the syntactic/combinatoric level. If the output of modification by expressions like very, quite, and so forth could serve as the input to further degree modification, or if the degree modifier itself could be the argument of another degree modifier, then we would predict multiple but distinct modifiers to be acceptable. This is not the case, however.

(i) a. *I was very quite surprised.

b. *I was quite really surprised.

c. *I was really very surprised. (*on degree modifier use of really; OK on adverbial use as in $I$ really was very surprised.)
}

The fact that degree modifier 'recursion' requires lexical identity of degree modifiers leads us to believe that this phenomenon involves a type of reduplication at the lexical level, the output of which is a degree modifier with a semantic type identical to that assigned to very in 64 . 
in $67 \mathrm{a}$ entails that the plates are not dry, and that the negation in $67 \mathrm{~b}$ entails that the glasses are wet, as illustrated by the contradictory continuations.

(67) a. The glasses are drier than the plates (\#though both are dry).

b. The glasses are not dry (\#but they're not wet either).

As shown by the contrast between $68 \mathrm{a}$ and $68 \mathrm{~b}$, these different uses of dry correlate with the acceptability of very. ${ }^{19}$

(68) a. This region of the country is very dry.

b. ??The glasses are very dry.

In examples in which the object being described does not promote one reading of dry over another, we can actually detect an ambiguity. Example 69a can be understood either as a claim that my hands have a certain skin quality, or as a claim about the amount of some liquid on them. Example $69 \mathrm{~b}$ is consistent only with the former interpretation, however, while $69 \mathrm{c}$ forces the latter.

(69) a. My hands are dry.

b. My hands are very dry.

c. My hands are partially dry.

There are, of course, apparent counterexamples to the generalization that very is infelicitous with absolute adjectives. For example, 70 might be used by a waiter to describe a restaurant that has an uncharacteristically small/large number of customers in it (depending on the choice of adjective). ${ }^{20}$

(70) The restaurant is very empty/full tonight.

However, we have already seen that absolute adjectives permit relative-like, imprecise interpretations, and there is evidence that this is what is going on here. In particular, very empty/full strongly implies not empty/full (a very empty restaurant is one with just a few diners, not one with no diners), indicating that whatever standard is being raised, it is not the absolute one.

When the context is incompatible with imprecise interpretations-when precision is important - the use of very with these adjectives is precluded. For example, consider a context involving an experiment in which some beakers are supposed to be filled with liquid to certain levels indicated by special markings, and others are supposed to be fully emptied of their contents. If an experimenter accidentally fills a beaker beyond the indicated 'full line', it would be infelicitous for her to report that situation by saying 71.

(71) \#Whoops! This beaker is very full. I'd better pour out some of that liquid.

\footnotetext{
19 These facts reflect Bolinger's observation that the adjective modified by very must express an 'essential' rather than 'accidental' property (Bolinger 1972:38-39). In most cases, adjectives with absolute scales are simply incompatible with very, though very modification is acceptable to the extent that the adjective can have a relative-like, 'essential' interpretation, as illustrated by the following examples.

(i) a. What we need is a man who is very able, very cheerful, and a good mixer. (Bolinger 1972: 39)

b. The department chair is very open to suggestions as to how to revamp the doctoral program.

c. She's is a very available person considering her busy schedule.

d. The baby is very awake. ( $\neq$ wide awake)

${ }^{20}$ Of course, very full is fully felicitous as a description of one's stomach after a big meal. We assume this to be a relative use of full, though, as indicated by the absence of a contradiction in an example like (i).

(i) I'm (very) full, but I saved some room for dessert.
} 
Likewise, once the experimenter has removed all of the contents from another beaker, she cannot felicitously report her action by saying 72 .

(72) \#OK, this beaker is very empty, so we're ready to use it.

For the time being, we remain neutral as to exactly how relative interpretations of absolute adjectives with very come about, since there are various, not entirely mutually exclusive, possibilities: an adjective might be vague with respect to the type of standard used to evaluate its applicability, with context serving to resolve the vagueness; an adjective might have become truly polysemous over time, with the degree modifier serving to disambiguate; or it may be that, faced with an ostensible conflict between the standard required by very and that associated with an adjective, speakers are able to reinterpret the adjective in such a way as to eliminate the conflict. What is important for our purposes is that when we control the context to force an absolute use, we see a clear sensitivity of the degree modifier to the relative/absolute standard distinction.

In fact, the restriction of very to relative adjectives follows from the Klein/Wheeler semantics implemented above in 64. According to our analysis, the semantic effect of very modification is to calculate the standard of comparison with respect to a comparison class based on the property denoted by the positive form of the adjectival predicate. For relative adjectives, this has the effect of raising the standard, as described above. But if we are correct in our claim that the standard relation always fixes the standard of an absolute adjective to the appropriate endpoint of the scale (depending on the adjective) regardless of comparison class (see $\$ 4.2$ ), then modification by very has absolutely no semantic effect: very $A$ and pos $A$ have exactly the same truth conditions. Assuming that semantically vacuous modification is anomalous, this explains the observed restriction of very to relative adjectives.

If our claims about very are correct, then we expect the class of deverbal gradable adjectives that accept modification by very to show properties of relative adjectives. In particular, they should show the entailment patterns observed with other relative adjectives (see §4.2). The following examples confirm these predictions.

(73) a. Klaus wasn't pleased by the report, though he did find a few positive aspects to it.

b. Klaus was pleased by the report, though he could have been happier with it.

(74) a. Mike wasn't frightened when he entered the ring, though he did feel a bit of apprehension.

b. Mike was frightened when he entered the ring, though he wasn't petrified.

(75) a. Gil wasn't relaxed, though he wasn't very nervous, either.

b. Gil felt relaxed, though he could have been more so.

At the same time, we expect that those deverbal adjectives that rejected very in favor of modification by much or well should show properties of absolute adjectives. We turn to this prediction now.

6.3. МUCH. We claim that much has a meaning that is close to that very-it effectively raises the standard of comparison associated with the unmodified form-but does so in a somewhat indirect way. Before presenting the analysis, we must substantiate a crucial generalization: deverbal adjectives that accept modification by much are minimum-standard absolute adjectives. This is illustrated by the following examples, which apply the entailment test for minimum standards ( $x$ is not $A$ entails $x$ has no amount of A-ness at all; see $\S 4.2$ ) to the participles that we earlier identified as acceptable with much (see 3 and Table 1). 
(76) a. \#The war was not desired, but certain parties hoped that a conflict would break out.

b. \#Your financial support is not needed, but it is necessary that we get a small contribution from you.

c. \#The film was not praised, but one critic said good things about it.

d. \#The problem was not talked about, though Frank mentioned it to his mother.

At the same time, adjectival participles whose entailments under proportional modification show them to have maximum standards (see §4.2), such as done, written, and filled, do not accept modification by much.

(77) a. ??The meat is much done. (partly done $\not \neq$ done)

b. ??The book is much written. (half written $\not \neq$ written)

c. ??The glass is much filled. (partially filled $\not \neq$ filled)

To account for the interpretation of much and its restriction to minimum-standard absolute adjectives, we propose the denotation in 78 , where $>$ !! is a context-dependent relation that means 'greater than by a large amount'. ${ }^{21}$

(78) $\llbracket \operatorname{much} \rrbracket=\lambda G \lambda x . \exists d\left[d>! ! \min \left(S_{G}\right) \wedge G(d)(x)\right]$

Strictly speaking, much just requires the degree argument of the adjective it modifies to be appropriately large. However, it crucially defines largeness in terms of the degree argument's relation to the minimal value on the adjective's scale, and so it is compatible only with adjectives that use lower closed scales in the first place. As we have seen, adjectives with such scale structures default to (minimum-standard) absolute adjectives, explaining the entailment patterns in 76.

As things stand, though, 78 places no restrictions on the upper end of an adjective's scale, predicting that much should in principle be compatible with totally closed scales as well as lower closed scales. All of the examples we have considered so far involve adjectives of the latter type, as shown by the fact that the relevant adjectives are unacceptable with proportional modifiers of maximality.

(79) a. ??a completely needed expense

b. ??a totally desired result

c. ??an absolutely discussed issue

It is unclear to what extent much is compatible with adjectives with totally closed scales, however. The examples in 77 suggest that this is generally not an option, and to date, we have found very few examples that suggest that it is, though the following is ostensibly one.

(80) ... a much-deserved rest (cf. fully deserved) (Commissioner Gordon, at the end of Batman episode 'Surf's Up/Joker's Under')

Although the reason for this apparent gap in the data remains to be explained, it may be a kind of elsewhere effect, given that the modifier well is restricted to predicates with totally closed scales, as we argue in the next section. Alternatively, it may ultimately be necessary to adjust the semantics for much to forbid it from applying to adjectives with totally closed scales.

\footnotetext{
${ }^{21}$ This is a shortcut on our part, since the context-dependence of much-as well as the possibility of modification by very (very much appreciated, very much loved, etc.) - suggests that it incorporates a relative gradable property as part of its meaning. Assuming that this property measures the size of the difference between the degree argument of the adjective and the lower endpoint of the scale (thus 'greater than zero by a large amount'), the core of our proposal remains the same.
} 
Before we move to our analysis of well, we need to address the fact that much also differs from very in that it is more often than not infelicitous with underived adjectives, even if they satisfy the lower closed scale requirement (cf. Bolinger 1972).

(81) a. *much $\{$ wet, open, dirty $\}$

b. *much \{aware of the difficulties, able to cope, available\}

It is unclear whether this is a superficial combinatorial constraint or whether it is indicative of a deeper semantic difference between derived and underived adjectives; interestingly, there is significant overlap in the few underived adjectives that permit much and those that permit well, as we discuss below. What is important for our purposes, however, is that both much and very can modify derived gradable adjectives. It is in this domain, we therefore assume, that we can clearly see the effects of the purely semantic restrictions that we have argued for here: very requires its adjectival argument to be relative, while much requires it to have a lower closed scale.

There is one important exception to the generalization that much cannot modify lexical adjectives, however, which arguably provides further support for our analysis: comparatives (and comparative-like expressions such as the same, different, and preferable) are compatible with much independent of the relative/absolute distinction of the base adjective, as illustrated by the examples in 82 .

(82) a. much \{wetter, more open, less dirty, etc.\} (minimum-standard absolute base)

b. much \{drier, more closed, less clean, etc.\} (maximum-standard absolute base)

c. much \{taller, happier, less expensive, etc. $\quad$ (relative base)

While it is possible that these examples represent a disinct use of much, the fact that it seems to have the same effect on truth conditions in these examples (it raises the standard provided by the comparative clause by a large amount) suggests an alternative interpretation of these facts: (unmodified) comparative constructions are semantically derived minimum-standard absolute adjectives.

This kind of interpretation of the comparative would involve giving up the traditional analysis of comparative constructions as expressions that take a gradable adjective and return a property of individuals (as described in \$6.1) and assuming instead that their role is to 'reset' the scale used by their adjectival argument. Specifically, we could assume that a comparative phrase morelless than $d_{c}$ (still treating this as a constituent, though this is by no means necessary) combines with a gradable adjective $A$ and returns an expression that has essentially the same meaning as $A$ and the same semantic type, but uses a scale whose minimal element is $d_{c}$ (see Rotstein \& Winter 2004:27 for a similar suggestion).

For example, the scale used by the predicate in 83 would be just that portion of the height scale that extends from Lee's (maximal) height upwards. The truth conditions of a comparative can then be stated in exactly the same terms as those of a minimumstandard absolute adjective: its argument is required to have a greater than minimum degree of the described property. In the case of 83 , the argument of the comparative must have some degree of taller than Lee-ness.

(83) Kim is taller than Lee (is).

Since the minimum in 83 is the (maximal) degree to which Lee is tall (the denotation of the comparative clause; see e.g. von Stechow 1984a), this will entail that Kim has a greater degree of height than Lee, giving us the truth conditions that we want. 
On this view, the degree argument of the comparative predicate-the expression that is semantically parallel to the degree argument of an unmodified, noncomparative adjective-corresponds to the degree to which the subject possesses the described property in excess of the compared object: it is a differential degree (see n. 16). In the case of an unmodified comparative, we may assume that this value is determined in the same way as for other minimum-standard adjectives, so that it is required to exceed the minimum value of the scale, that is, to be greater than the degree denoted by the comparative clause, as described above.

For modified comparatives, however, we expect both that modifiers sensitive to minimum values like much should be acceptable, and that modifiers should always measure the degree of difference between the subject and the compared object. Indeed, this is the case with much: 84 requires the amount of height Kim has in excess of Lee to be large, but does not entail that Kim (or Lee) has a lot of height.

(84) Kim is much taller than Lee (but both are very short).

Likewise, measure phrases in comparatives measure only the difference between the compared objects, not the absolute measurements of either. Thus five feet in 85 measures the amount to which Yao's height exceeds that of Julian's, not Yao's height in general.

(85) Yao is five feet taller than Julian.

Demonstrating conclusively that this is the right way of analyzing comparatives and providing a comprehensive compositional analysis along these lines go beyond the scope of this article. However, the parallels between comparatives and minimum-standard adjectives and the interpretation of modifiers in comparatives suggest that this is an approach that should receive serious consideration in future work.

6.4. WELL. We now turn to a rather different kind of degree modification. In contrast to the other modifiers, well combines felicitously with adjectives that have totally closed scales, as illustrated by the examples in 86 and $87 .^{22}$

(86) a. We are well aware of the difficulties.

b. They are well able to solve their own problems.

c. The bud was well open. (Bolinger 1972:43)

(87) a. We are half/mostly aware of the difficulties.

b. They are half/mostly able to solve their own problems.

c. The bud was half/mostly open.

In particular, we see from the acceptability of proportional modifiers that those adjectival participles that accept modification by well have closed scales.

(88) a. well \{acquainted, documented, understood, publicized, written, etc.\}

b. half/mostly \{acquainted, documented, understood, publicized, written, etc.

An important difference between well on the one hand and very and much on the other is that the output of well modification can be the input to a full range of further degree modification.

\footnotetext{
${ }^{22}$ Not all nonderived adjectives with totally closed scales permit modification by well, however, which may be due to an independent morphosyntactic preference for well to modify participles. Alternatively, this restriction may be due to a semantic requirement that well have access to an event variable derived as described below or present in the fine-grained lexical semantics of the modified expression, as proposed in McNally \& Kennedy 2002, 2005. Something similar may be going on with much (cf. the discussion above), though it does seem that well is somewhat more permissive than much when it comes to modification of underived adjectives; see Bolinger 1972:38ff., 44.
} 
(89) a. Sam is more well able to cope with the situation than is his brother.

b. They remained very/quite/only too/hardly well aware of the difficulties that might arise from their analysis.

c. Martin Beck is very well acquainted with the facts of the case.

d. The facts are hardly well understood.

e. The concert was quite well publicized.

Although in many cases it may be difficult to determine whether the degree modifier or comparative has combined with just well or with the well A constituent, comparatives show that the latter type of combination is indeed possible: 89 a entails that Sam is well able to cope, whereas 90 , in which the use of a suppletive form clearly shows that the comparative combines first (and exclusively) with well, entails only that Sam is able to cope to some degree. (See also Bolinger 1972:268ff. for related comments on the difficulty of determining what degree modifiers in fact modify.)

(90) Sam is better able to cope with the situation than is his brother.

These facts strongly indicate that well is not of the same syntactic or semantic category as very and much, even though its semantic effects are similar. Instead, the facts in 89 indicate that well denotes a function from (gradable) adjective meanings to adjective meanings. But what kind of function?

Four facts are relevant to answering this question. First, the fact that the output of well modification supports modification by very shows that the resulting complex expression must be a relative gradable predicate. Second, although a well A construction can be further modified by a range of degree morphemes, there is a systematic exception. Proportional modification is infelicitous, as shown by 91 , indicating that the well $A$ complex uses an open scale.

(91) a. ??Martin Beck is partially/half/completely well acquainted with the facts.

b. ??The concert was partially/half/completely well publicized.

c. ??The facts are partially/half/completely well understood.

Third, an utterance of $x$ is well $A$ presupposes that $x$ has some degree of $A$-ness. In the case of a minimum-standard adjective like acquainted, this has the result that $x$ is well $A$ presupposes that $x$ is $A$ (given the truth conditions associated with minimum standards; see $34 \mathrm{a}$ ): each of $92 \mathrm{a}-\mathrm{c}$ requires $92 \mathrm{~d}$ to be true and is inconsistent with the truth of $92 \mathrm{e}$.

(92) a. Martin Beck is well acquainted with the facts.

b. Is Martin Beck well acquainted with the facts?

c. Martin Beck is not well acquainted with the facts.

d. Martin Beck is acquainted with the facts.

e. Martin Beck is unacquainted with the facts.

In the case of a maximum-standard adjective like loaded (with an incremental theme subject; see §5.3), 93a-c clearly presuppose that the hay has some degree of loadedness: it is inconsistent to assert 93a-c and 93e.

(93) a. The hay is well loaded.

b. Is the hay well loaded?

c. The hay is not well loaded.

d. The hay is loaded.

e. The hay is unloaded.

However, although the examples in 93a-c strongly imply $93 \mathrm{~d}$, this is more likely an implicature than a presupposition. In a context in which a foreman is watching a truck 
being loaded with hay, for example, it is perfectly felicitous for him to utter any of $93 \mathrm{a}-\mathrm{c}$ when it is clear that the loading is not yet complete, so that $93 \mathrm{~d}$ is false. Likewise, the inference to $93 \mathrm{~d}$ from 93 a can be canceled by adding so far, as in 94a.

(94) a. The hay is well loaded so far.

b. Martin Beck is well acquainted with the facts so far.

This is not the case with a minimum-standard adjective: 94b still presupposes that Martin Beck is acquainted with the facts.

Finally, there is a clear semantic relation between the degree-modifier use of well and its adverbial use, as illustrated by the examples in 95 .

(95) a. We acquainted Beck well with the facts.

b. Beck is someone well acquainted with the facts.

If a person is well acquainted with a set of facts, then it is also true that that person has been acquainted well with those facts.

With these considerations in mind, we propose an interpretation of well as an expression that takes a closed-scale adjective as input and returns a new gradable adjective meaning based on the relative adjective good, which we assume underlies well. Specifically, building on the similarity in meaning between $95 \mathrm{a}$ and $\mathrm{b}$, we propose that the derived predicate measures the goodness of the event that is related to the degree to which the subject has the property named by the adjective. What exactly it means for an event to count as good is of course indeterminate, a point to which we return below, but one salient measure is the degree to which an object possesses the relevant property as a result of participating in the event. This, we claim, is the essence of the degree interpretation of well.

The details are spelled out in the denotation in 96, where $G_{[0,1]}$ indicates that well is restricted to taking a closed-scale gradable predicate as input, and $\epsilon$ is a function from degrees to events based on the homomorphic mapping between events and scales that we discussed in $\S 5.1$; specifically, $\epsilon\left(\iota d^{\prime}\left[G_{[0,1]}\left(d^{\prime}\right)(x)\right]\right)$ in 96 is the event that corresponds to $x$ becoming $G_{[0,1]}$ to degree $d^{\prime}$.

(96) $\llbracket$ well $\rrbracket=\lambda G_{[0,1]} \lambda d \lambda x \cdot \operatorname{good}\left(\epsilon\left(\mathrm{\iota} d^{\prime}\left[G_{[0,1]}\left(d^{\prime}\right)(x)\right]\right)\right)=d$

For example, well acquainted with $y$ denotes a relation between a degree $d$ and individual $x$ such that the goodness of the event of $x$ becoming acquainted with $y$ to degree $d$ ' equals $d$. If this expression is used as a main predicate, it must be further modified by the pos morpheme (like any other gradable predicate), so that a sentence such as Beck is well acquainted with the facts is true just in case the event of Beck becoming acquainted with the facts qualifies as good with respect to some appropriate comparison class and some metric of goodness, for example, because it was very thoroughly carried out.

The presuppositions of well modification - that the argument of the well A complex has some degree of $A$-ness-follow from the natural assumption that the 'good' component of well's meaning (the measure function symbolized by good in 96) must be given a nonempty input. Although an object could in principle be mapped to the zero point of a closed scale, in the case of a deverbal adjective, this would mean that the object has not participated in the event named by the verb at all. If this were the case, then the $\epsilon$ function would not return a value and the requirements of good would not be met. In order to satisfy these requirements, then, it must be the case that the subject has some nonzero degree of the adjectival property, generating the presuppositions observed above.

More needs to be said about the relation between well and the event introduced by the gradable predicate, an issue that we investigate in detail in McNally \& Kennedy 
$2002,2005 .^{23}$ For the purposes of this article, however, it is enough to observe that 96 has the desired consequence of turning a closed-scale adjective into an open-scale one, since the degree argument of well $A$ is a degree on the open scale associated with good rather than a degree on the closed scale associated with the modified adjective. We thus derive the impossibility of proportional modification of well $A$ and the acceptability of further modification by very.

This aspect of 96 also makes a new prediction: since there are various ways in which an eventuality might count as good, we should see a certain amount of polysemy in well modification. In fact, expressions of the form well A typically have two interpretations, as pointed out in Kennedy \& McNally 1999. In addition to the 'high degree' reading that we have been focusing on here, well has a 'manner' reading that means something like 'in a good way'. The following titles of articles from the world wide web illustrate this apparent polysemy.

(97) a. Well-documented, yet little known facts about dams and reservoirs (http://www.sandelman.ottawa.on.ca/dams/readme.html)

b. Well documented patterns reduce future labour (http://www.expressitpeople.com/20011119/management3.htm)

The point of the first article is that there is a large volume of information about the harmful effects of large dam and reservoir projects outside of the narrow domain of engineering literature (which is typically ignored); well is clearly being used here to indicate a high degree of documentation. The second article is a discussion of patternoriented methodologies in software development. It argues that such a methodology will be successful only if the relevant patterns are carefully documented; here well has a manner interpretation. See McNally \& Kennedy 2002, 2005 for an explanation of the degree vs. manner interpretations of well in terms of the role played by the object in the event.

7. Conclusion. We have argued on the basis of facts involving the acceptability and interpretation of gradable adjectives in different contexts, entailment patterns, and in particular the distribution and interpretation of degree modifiers for the linguistic relevance of two aspects of gradable adjective meaning - scale structure and the context-dependence of the standard of comparison-and we have presented a semantics for the degree modifiers very, much, and well that makes crucial use of these distinctions. In addition, we have shown that an adjective's scale structure is not always arbitrary, but rather there are strong correlations between the structure of the scale and the nature of the standard value, between the event structure of the verb from which a participial adjective is derived and the scale structure of that adjective, and between the part structure of an adjective's argument and the scale structure of that adjective.

This article clearly leaves many things to be explored. One question is to what extent the orientation of the standard can be predicted in cases of adjectives not obviously related to events. In addition, there are many more degree modifiers that merit investigation, and it remains to generalize the semantic analyses provided here for much and well to the uses of these expressions as modifiers of other syntactic categories. One of the most important issues, however, is how scale structure should be encoded in the

\footnotetext{
${ }^{23}$ In that work, we develop a more articulated analysis of the semantics of well that shares its basic claims about meaning with the analysis presented here, but that is formalized within the generative lexicon framework (Pustejovsky 1995), allowing for a specific characterization of how well accesses the event variable introduced by its adjectival argument. Among other things, this analysis makes it possible to establish a relationship between the degree and manner interpretations of well.
} 
lexical semantic representations of members of different grammatical categories. At the very least, lexical entries should be structured to allow us to explain the influence that both linguistic and extralinguistic context can have on the scale with respect to which an adjective is evaluated, and they should also make clear how the scale structures of derivationally related expressions (verbs and deverbal adjectives, for instance) are related.

Of most general interest to the study of cross-categorial similarities in meaning, the facts we have analyzed here clearly reinforce the hypothesis put forward by Bolinger and Sapir that gradability is a feature of grammatical categories other than adjectives. Future research should be directed toward increasing our understanding of how exactly this central semantic property is encoded cross-categorially.

\section{REFERENCES}

Barker, Chris. 2002. The dynamics of vagueness. Linguistics and Philosophy 25.1-36.

Bartsch, Renate, and Theo Vennemann. 1973. Semantic structures: A study in the relation between syntax and semantics. Frankfurt: Athäenum.

Bierwisch, MANFRED. 1989. The semantics of gradation. Dimensional adjectives, ed. by Manfred Bierwisch and Ewald Lang, 71-262. Berlin: Springer.

Bolinger, Dwight. 1972. Degree words. The Hague: Mouton.

Borer, Hagit. 1998. Deriving passive without theta roles. Morphological interfaces, ed. by Stephen Lapointe, Diane K. Brentari, and Patrick M. Farrell, 60-99. Stanford, CA: CSLI Publications.

Bresnan, JoAn. 1973. Syntax of the comparative clause construction in English. Linguistic Inquiry 4.275-343.

Cresswell, Max J. 1977. The semantics of degree. Montague grammar, ed. by Barbara Partee, 261-92. New York: Academic Press.

Cruse, D. Allan. 1986. Lexical semantics. Cambridge: Cambridge University Press.

Demonte, Violeta. 2004. Merge of adjectives in DP and interface conditions. Madrid: Universidad Autónoma de Madrid, MS.

DoetJes, Jenny. 1997. Quantifiers and selection. Leiden: Rijksuniversiteit Leiden dissertation.

Dowty, DAvid R. 1991. Thematic proto-roles and argument selection. Language 67.547-619.

GAZDAR, GERALD. 1980. A phrase structure syntax for comparative clauses. Lexical grammar, ed. by Teun Hoekstra, Harry van der Hulst, and Michael Morgan, 165-79. Oxford: Blackwell.

GrafF, Delia. 2000. Shifting sands: An interest-relative theory of vagueness. Philosophical Topics 20.45-81.

Hay, Jen. 1998. The non-uniformity of degree achievements. Paper presented at the 72nd annual meeting of the Linguistic Society of America, New York City.

Hay, Jen; Christopher Kennedy; and Beth Levin. 1999. Scale structure underlies telicity in 'degree achievements'. Semantics and Linguistic Theory 9.127-44.

Hazout, ILAN. 1995. Comparative ellipsis and logical form. Natural Language \& Linguistic Theory 13.1-37.

Heim, IRENE. 1985. Notes on comparatives and related matters. Austin: University of Texas, MS.

Heim, IRENe. 2000. Degree operators and scope. Semantics and Linguistic Theory 10.40-64.

Heim, Irene, and Angelika Kratzer. 1998. Semantics in generative grammar. Oxford: Blackwell.

Hellan, LARS. 1981. Towards an integrated analysis of comparatives. Tübingen: Narr.

Hendriks, Petra. 1995. Comparatives in categorial grammar. Groningen: University of Groningen dissertation.

JACKENDOFF, RAY. 1996. The proper treatment of measuring out, telicity, and perhaps even quantification in English. Natural Language \& Linguistic Theory 14.305-54.

Kamp, J. A. W. 1975. Two theories of adjectives. Formal semantics of natural language, ed. by Edward Keenan, 123-55. Cambridge: Cambridge University Press. 
Kennedy, Christopher. 1999a. Gradable adjectives denote measure functions, not partial functions. Studies in the Linguistic Sciences 29.65-80.

Kennedy, Christopher. 1999b. Projecting the adjective: The syntax and semantics of gradability and comparison. New York: Garland. [Santa Cruz: University of California, Santa Cruz dissertation, 1997.]

Kennedy, Christopher. 2001. Polar opposition and the ontology of 'degrees'. Linguistics and Philosophy 24.33-70.

KenNedy, CHRISTOPHER. 2002. Comparative deletion and optimality in syntax. Natural Language \& Linguistic Theory 20.553-621.

Kennedy, Christopher. 2003. Towards a grammar of vagueness. Paper presented at the Princeton Semantics Workshop, May 16-17, Princeton, NJ.

Kennedy, Christopher, and Louise McNally. 1999. From event structure to scale structure: Degree modification in deverbal adjectives. Semantics and Linguistic Theory 9.163-80.

Klein, Ewan. 1980. A semantics for positive and comparative adjectives. Linguistics and Philosophy 4.1-45.

KLeIN, Ewan. 1991. Comparatives. Semantik: Ein internationales handbuch der zeitgenössischen forschung, ed. by Arnim von Stechow and Dieter Wunderlich, 673-91. Berlin: Walter de Gruyter.

Knowles, JoHn. 1974. The degree adverbial. Journal of English Linguistics 8.21-31.

KrifKa, Manfred. 1989. Nominal reference, temporal constitution and quantification in event semantics. Semantics and contextual expression, ed. by Renate Bartsch, Johann van Benthem, and Peter van Emde Boas, 75-115. Stanford, CA: CSLI Publications.

KRIFKA, MANFRED. 1992. Thematic relations as links between nominal reference and temporal constitution. Lexical matters, ed. by Ivan Sag and Anna Szabolcsi, 29-53. Stanford, CA: CSLI Publications.

KrifKA, MANFRED. 1998. The origins of telicity. Events and grammar, ed. by Susan Rothstein, 197-235. Dordrecht: Kluwer.

Landman, Fred. 1989. Groups, 1. Linguistics and Philosophy 12.559-605.

Lasersohn, Peter. 1995. Plurality, conjunction and events. Dordrecht: Kluwer.

Lasersohn, Peter. 1999. Pragmatic halos. Language 75.522-51.

LEHRER, AdRIENNE. 1985. Markedness and antonymy. Journal of Linguistics 21.397-429.

LEVIN, BETH, and MALKA RAPPAPORT. 1986. The formation of adjectival passives. Linguistic Inquiry 17.623-61.

LEwIS, DAvID K. 1979. Scorekeeping in a language game. Journal of Philosophical Logic 8.339-59.

Link, GoDEHARD. 1983. The logical analysis of plurals and mass terms: A lattice theoretical approach. Meaning, use, and interpretation of language, ed. by Rainer Bäuerle, Christoph Schwarze, and Arnim von Stechow, 302-23. Berlin: Walter de Gruyter.

Ludlow, Peter. 1989. Implicit comparison classes. Linguistics and Philosophy 12.519-33.

McConnell-Ginet, Sally. 1973. Comparative constructions in English: A syntactic and semantic analysis. Rochester, NY: University of Rochester dissertation.

McNally, Louise, and Christopher Kennedy. 2002. Degree vs. manner 'well': A case study in selective binding. Cuadernos de lingüística 9, ed. by María Jesús Arche, Antonio Fábregas, and Augusto M. Trombetta. Madrid: Instituto Universitario Ortega y Gasset.

McNally, Louise, and Christopher Kennedy. 2005. Degree vs. manner 'well': A case study in selective binding. Generative approaches to the lexicon, ed. by Pierrette Bouillon, Hitoshi Isahara, Kyoko Kanzaki, Chungmin Lee, and James Pustejovsky. Dordrecht: Kluwer, to appear.

Paradis, Carita. 2001. Adjectives and boundedness. Cognitive Linguistics 12.47-65.

Pustejovsky, James. 1995. The generative lexicon. Cambridge, MA: MIT Press.

Ramchand, Gillian C. 1997. Aspect and predication. Oxford: Clarendon Press.

Rotstein, CARmen, and YoAD WInTER. 2004. Total adjectives vs. partial adjectives: Scale structure and higher-order modifiers. Natural Language Semantics 12.259-88.

Rullmann, Hotze. 1995. Maximality in the semantics of wh-constructions. Amherst: University of Massachusetts dissertation.

SAPIR, EdwARD. 1944. Grading: A study in semantics. Philosophy of Science 11.93-116. 
Seuren, Pieter A. M. 1973. The comparative. Generative grammar in Europe, ed. by Ferenc Kiefer and Nicolas Ruwet, 528-64. Dordrecht: Reidel.

Seuren, Pieter A. M. 1978. The structure and selection of positive and negative gradable adjectives. Chicago Linguistic Society 14.336-46.

Stanley, Jason. 2000. Context and logical form. Linguistics and Philosophy 23.391-434.

STANLEY, JASON. 2002. Nominal restriction. Logical form and language, ed. by Georg Peter and Gerhard Preyer, 365-68. Oxford: Oxford University Press.

Sybesma, Rynt. 1999. The Mandarin VP. Boston: Kluwer.

Tenny, CARol L. 1995. How motion verbs are special: The interaction of semantic and pragmatic information in aspectual verb meanings. Pragmatics and Cognition 3.31-73.

Tsujimura, NAtsuko. 2001. Degree words and scalar structure in Japanese. Lingua 111.29-52.

Unger, Peter. 1975. Ignorance. Oxford: Clarendon Press.

VANDEN Wyngaerd, Guido. 2001. Measuring events. Language 77.61-90.

von Stechow, ARnim. 1984a. Comparing semantic theories of comparison. Journal of Semantics 3.1-77.

vON STECHOw, ArNim. 1984b. My reply to Cresswell's, Hellan's, Hoeksema's and Seuren's comments. Journal of Semantics 3.183-99.

WeChSler, STEPhen. 2005. Resultatives under the 'event-argument homomorphism'. The syntax of aspect, ed. by Nomi Erteschik-Shir and Tova Rapoport. Oxford: Oxford University Press, to appear.

Wheeler, Samuel. 1972. Attributives and their modifiers. Noûs 6.310-34.

WiLliamson, Timothy. 1994. Vagueness. London: Routledge.

Yoon, Yoongeun. 1996. Total and partial predicates and the weak and strong interpretations. Natural Language Semantics 4.217-36.

Kennedy

Department of Linguistics

Northwestern University

2016 Sheridan Rd.

Evanston, IL 60208

[kennedy@ northwestern.edu]

McNally

Department de Traducció i Filologia

Universitat Pompeu Fabra

La Rambla, 30-32

08002 Barcelona

Spain

[louise.mcnally@upf.edu]
[Received 9 July 2002;

revision invited 24 February 2003; revision received 21 January 2004; accepted 20 July 2004] 